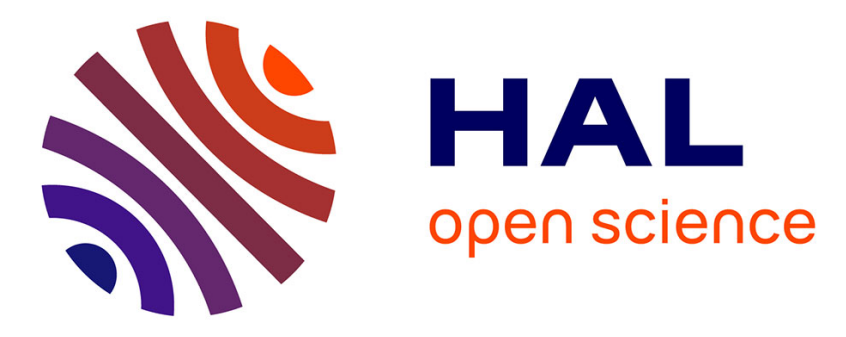

\title{
Mapping biodiversity in three-dimensions challenges marine conservation strategies: The example of coralligenous assemblages in North-Western Mediterranean Sea
}

Aggeliki Doxa, Florian Holon, Julie Deter, Sébastien Villéger, Pierre Boissery, Nicolas Mouquet

\section{To cite this version:}

Aggeliki Doxa, Florian Holon, Julie Deter, Sébastien Villéger, Pierre Boissery, et al.. Mapping biodiversity in three-dimensions challenges marine conservation strategies: The example of coralligenous assemblages in North-Western Mediterranean Sea. Ecological Indicators, 2016, 61 (2), pp.1042-1054. 10.1016/j.ecolind.2015.10.062 . hal-01444069

\author{
HAL Id: hal-01444069 \\ https://hal.science/hal-01444069
}

Submitted on 26 Feb 2022

HAL is a multi-disciplinary open access archive for the deposit and dissemination of scientific research documents, whether they are published or not. The documents may come from teaching and research institutions in France or abroad, or from public or private research centers.
L'archive ouverte pluridisciplinaire HAL, est destinée au dépôt et à la diffusion de documents scientifiques de niveau recherche, publiés ou non, émanant des établissements d'enseignement et de recherche français ou étrangers, des laboratoires publics ou privés. 


\title{
Mapping biodiversity in three-dimensions challenges marine conservation strategies: The example of coralligenous assemblages in North-Western Mediterranean Sea
}

\author{
Aggeliki Doxa ${ }^{\mathrm{a}, *}$, Florian Holon ${ }^{\mathrm{a}, \mathrm{b}}$, Julie Deter $^{\mathrm{a}, \mathrm{b}}$, Sébastien Villéger ${ }^{\mathrm{c}}$, Pierre Boissery ${ }^{\mathrm{d}}$, \\ Nicolas Mouquet ${ }^{\mathrm{a}}$ \\ a Université de Montpellier/Institut des Sciences de l'Evolution (ISEM), UMR 5554 CNRS IRD, Campus Triolet de l'Université de Montpellier, \\ 34095 Montpellier Cedex 5, France \\ ${ }^{\mathrm{b}}$ Andromède Océanologie, 7 place Cassan, 34280 Carnon, France

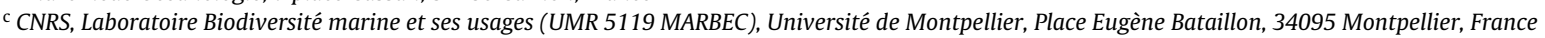 \\ d Agence de l'Eau Rhône-Méditerranée-Corse, Délégation de Marseille, Immeuble le Noailles, 62 La Canebière, 13001 Marseille, France
}

Keywords:

Alpha diversity

Beta diversity

Community dissimilarities

Coralligenous outcrops

Marine conservation

French Mediterranean coast

Multi-facet diversities

Vertical diversity

\section{A B S T R A C T}

Multi-facet diversity indices have been increasingly widely used in conservation ecology but congruence analyses both on horizontal and vertical axes have not yet been explored. We investigated the vertical and horizontal distributions of $\alpha$ and $\beta$ taxonomic (TD), functional (FD) and phylogenetic diversity (PD) in a three-dimensional structured ecosystem. We focused on the Mediterranean coralligenous assemblages which form complex structures both vertically and horizontally, and are considered as the most diverse and threatened communities of the Mediterranean Sea. Although comparable to tropical reef assemblages in terms of richness, biomass and production, coralligenous assemblages are less known and more rarely studied, in particular because of their location in deep waters. Our study covers the entire range of distribution of coralligenous habitats along the French Mediterranean coasts, representing the most complete database so far developed for this important ecosystem. To our knowledge, this is the first analysis of spatial diversity patterns of marine biodiversity on both horizontal and vertical scales.

Our study revealed that taxonomic diversity differed from functional and phylogenetic diversity patterns at the station level, the latter two being strongly structured by depth, with shallower stations generally richer than deeper ones. Considering all stations, phylogenetic diversity was less congruent to taxonomic diversity (Pearson's correlation of $r=0.48$ ) but more congruent to functional diversity $(r=0.69)$ than randomly expected. Similar congruence patterns were revealed for stations deeper than $50 \mathrm{~m}$ ( $r=0.44$ and $r=0.84$, respectively) but no significantly different congruence level than randomly expected was revealed among diversity facets for more shallow stations. Mean functional $\alpha-$ and $\beta$ diversity were lower than phylogenetic diversity and even lower than taxonomic $\alpha$ - and $\beta$-diversity for both vertical and horizontal scales. Low FD and PD values at both $\alpha$ - and $\beta$-diversity indicated functional and phylogenetic clustering. Community dissimilarities ( $\beta$-diversity) increased over depth especially in central and eastern part of the French Mediterranean littoral and in northern Corsica, indicating coralligenous vertical structure within these regions. Overall horizontal $\beta$-diversity was higher within the 50-70 m depth belts.

We conclude that taxonomic diversity alone is inadequate as a basis for setting conservation goals for this ecosystem and additional information, at least on phylogenetic diversity, is needed to preserve the ecosystem functioning and coralligenous evolutionary history. Our results highlight the necessity of considering different depth belts as a basis for regional scale conservation efforts. Current conservation approaches, such as the existing marine protected areas, are insufficient in preserving coralligenous habitats. The use of multi-facet indices should be considered, focusing on preserving local diversity patterns and compositional dissimilarities, both vertically and horizontally. 


\section{Introduction}

A wide range of animal and plant species exhibit a vertically stratified distribution pattern in terrestrial ecosystems, with most documented examples treating variations in species distributions along the vertical gradient from canopy to understory (ex. small mammals (Pardini et al., 2005), butterflies (Walla et al., 2004; Molleman et al., 2006) ants (Vasconcelos and Vilhena, 2006) and saproxylic species (Wermelinger et al., 2007)). Similar vertical stratification has been documented along the water column in marine ecosystems, for fish larvae and zooplankton groups (Pilar Olivar et al., 2010), as well as in bacterial and archaeal communities (Ghiglione et al., 2008; Ye et al., 2009; Zinger et al., 2011). In marine ecosystems, most of the key abiotic factors (light, water movement, nutrient availability, sedimentation and temperature) vary strongly along bathymetric (vertical) as well as horizontal gradients, thus structuring species' community composition (Bonecker et al., 2014). Whether vertical and/or horizontal gradients structure more species communities may significantly influence conservation efficiency but such aspects still remain poorly documented.

In addition to being a proxy of environmental gradients and structuring species' ecological niche, depth is also related to human pressure. In the Mediterranean basin, most human activities that may have an impact on marine ecosystems are depthrelated; recreational fishing, navigation and/or diving activities, for instance, take place in relatively shallow waters (less than $50 \mathrm{~m}$ ), thus making some depth belts more exposed to disturbances than others (Meinesz and Blanfuné, 2015). However, other sources of disturbances, such as professional fishing, mechanistic destruction (ex. installation of underwater cables) and pollution from terrestrial or marine sources can act as a disturbance in even deeper zones (especially in $>50 \mathrm{~m}$ depth belts) (Grall and Hall-Spencer, 2003; Meinesz and Blanfuné, 2015). Finally, as recently reviewed in a 30-year survey, depth remains an important factor for marine conservation efforts in the Mediterranean basin, with more focus being recently given to ecosystems deeper than $50 \mathrm{~m}$ (Meinesz and Blanfuné, 2015). However, the network of marine protected areas (MPAs) lacks a sufficiently specific planning focus and specific ecological criteria for the selection of the target depth belts. Most Mediterranean MPAs were established on the basis of limited ecological, social, and economic data (Claudet and Pelletier, 2004; Claudet et al., 2006).

While some taxonomic groups, such as fish and seagrass meadow communities, have been studied extensively within the Mediterranean basin (Ruíz et al., 2009; Mouillot et al., 2011) and used as indicators for European environmental policies (Devlin et al., 2007; Gobert et al., 2009; Personnic et al., 2014), deeper marine ecosystems remain poorly known (Cartes et al., 2004). Among the most vulnerable and diverse ecosystems within the Mediterranean basin, coralligenous outcrops are comparable in species richness and abundance to tropical reef assemblages (Bianchi and Morri, 2000; Ballesteros, 2006). Coralligenous reefs are found between 20 and $120 \mathrm{~m}$ depth and are composed of a hard substrate of concretions of biogenic origin, produced mainly by the accumulation of encrusting algae growing at low light levels (Garrabou and Ballesteros, 2000). Little was known about this highly diverse ecosystem until recently (Ballesteros, 2006), and it is only during the last few years that technical diving improvements have enabled their systematic surveying over extended spatial zones (Deter et al., 2012a,b). As they have little to no resilience against disturbances, due to their particularly low rate of development of only $0.006-0.83 \mathrm{~mm} / \mathrm{yr}$ in the western Mediterranean Sea (Littler, 1991; Sartoretto et al., 1996), the risk of extinction may be high, given current and future global changes. However, no regional diversity analysis has been conducted to date on this important Mediterranean habitat.
Although taxonomic indices have traditionally been, widely used in conservation, recent research shows that other biodiversity facets, such as species ecological traits (functional diversity) and species evolutionary history (phylogenetic diversity) are important to ecosystem functioning (Hooper et al., 2005; Mouquet et al., 2012; Srivastava et al., 2012). More importantly, the spatial patterns of these two biodiversity facets are often not congruent with taxonomic diversity patterns (Forest et al., 2007; Devictor et al., 2010a), since the three facets result from different processes in community assembly, and in turn provide relevant inputs for the identification of conservation targets (Devictor et al., 2010b; Mouillot et al., 2011). It has thus been increasingly widely acknowledged that conservation planning should focus on preserving ecosystem processes and functions and more effort should be made to identify areas that preserve functional traits and evolutionary legacies at various spatial scales (Abdulla et al., 2009; Coll et al., 2012). However, the multidimensionality of diversity is not yet reflected in existing conservation planning. MPAs, for instance, used as one of the main conservation tools worldwide, are designated on the basis of a few charismatic taxa (e.g. fish, mammals), not via an integrated ecosystemic approach (Fraschetti et al., 2005).

Exploring the vertical vs horizontal distribution patterns for all three diversity facets is a completely unexplored field. We chose to address these questions with regard to the Mediterranean coralligenous assemblages because of their complex structure, both vertically and horizontally, and their high level of richness and vulnerability. In order to understand and preserve the three-dimensional nature of these high diversity assemblages, it is urgent to examine compositional dissimilarity levels along both vertical and horizontal gradients, especially since all previous and existing conservation efforts have focused on rather shallow coastal areas $(<40 \mathrm{~m})$, disregarding deeper ecosystems (Abdulla et al., 2009). To address this conservation issue, a preliminary step is to combine measures of diversity distribution (community diversity $=\alpha$ diversity and between-community dissimilarities $=\beta$ diversity) (Legendre et al., 2009; Veech and Crist, 2010) in the three dimensions. To our knowledge, this has to date never been done using the three facets of diversity for any studied terrestrial or marine ecosystem.

We assessed the taxonomic, functional and phylogenetic diversity of North-Western Mediterranean coralligenous assemblages along both horizontal $(1700 \mathrm{~km})$ and vertical $(73 \mathrm{~m})$ gradients, which represents the entire distribution of coralligenous habitats in the French Mediterranean. In comparison with previous studies (Balata et al., 2006; Piazzi et al., 2009; Piazzi and Balata, 2011), which considered a small fraction of the possible depths $(30-40 \mathrm{~m})$ at which one may encounter the coralligenous concretions, our database represents the most complete distribution range ever used for the studied organisms. Our aim is to answer the following questions: (1) How are the three facets of diversity spatially distributed and what is their degree of congruence? (2) How does spatial distribution of biodiversity vary from the horizontal to the vertical axis? (3) To what extent does the existing network of marine protected areas encapsulate the multidimensionality of coralligenous biodiversity (vertical/horizontal, taxonomic/functional/phylogenetic)? Our results have important implications not only for the conservation biology of coralligenous assemblages but also for any kind of ecosystem organised along both horizontal and vertical axes.

\section{Materials and methods}

\subsection{Study area and coralligenous assemblages monitoring}

The coralligenous monitoring programme started in 2010 and is still ongoing. Three regions, composing the French coralligenous distribution area, are surveyed: (i) eastern Provence-Alpes-Côte 


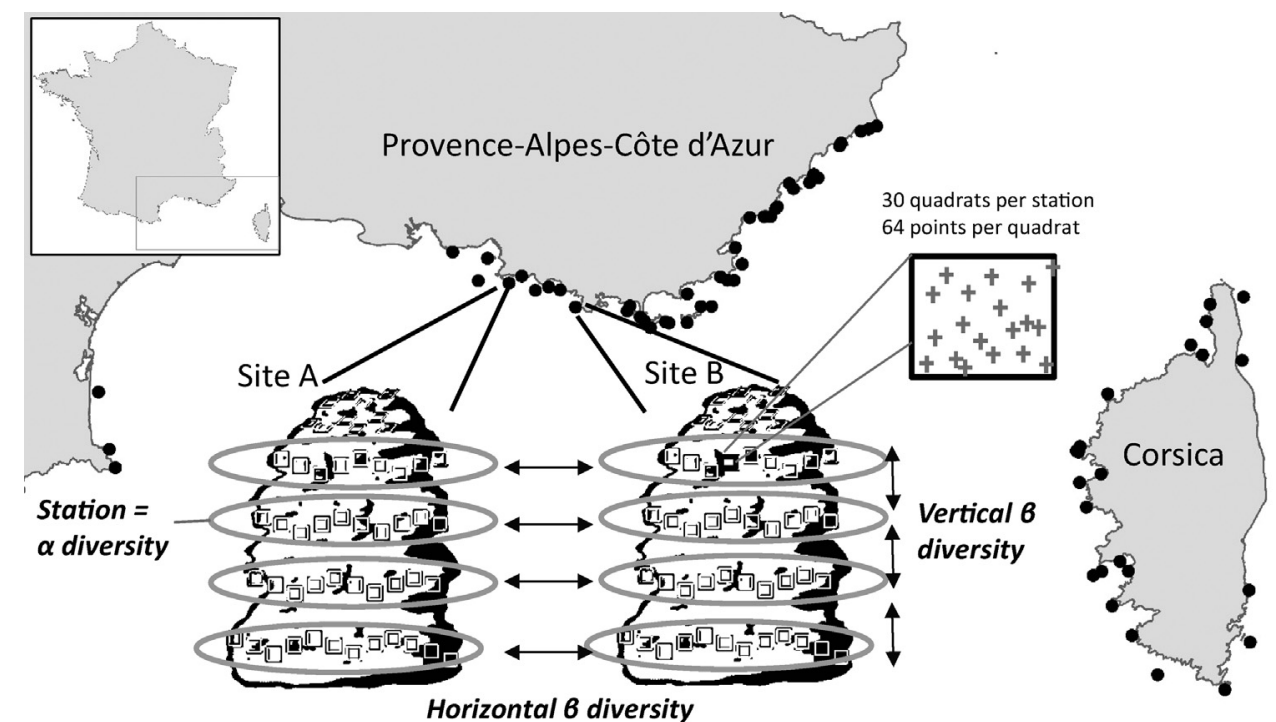

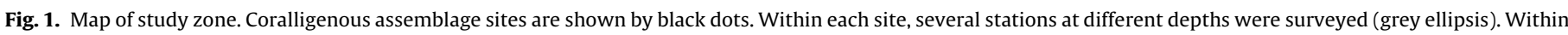

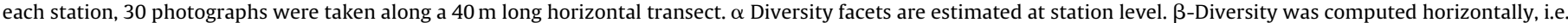
among stations within the same depth category and vertically, i.e. among stations within the same region.

d'Azur (PACA), (ii) Corsica and (iii) Languedoc-Roussillon and western PACA regions. Given the complexity of the survey, monitoring is conducted every year during June in one of these regions. Three consecutive years are thus needed to obtain comparable data for the entire monitored area. We used data from 2010 to 2012 which corresponded to one year of survey per region. During this period, a total of 120 stations were surveyed along the French Mediterranean coast (Fig. 1). In these ecosystems, temporal changes from one year to another are rare compared to spatial changes (Garrabou et al., 2002; Deter et al., 2012a), except in case of extreme stochastic disturbances (Garrabou et al., 2009; Teixidó et al., 2013). No such extreme event has occurred along the French coast since 2006, so no time effect was considered in our analysis.

Monitored stations were chosen as follows. First, all areas, where coralligenous assemblages could potentially occur were identified on the basis of a bathymetric cartographical analysis (http:// observatoire-mer.fr/en/surfstat.html). Then, 69 sites (Fig. 1) were chosen to represent different environmental conditions, according to physico-chemical characteristics of coastal water bodies. Following the European Water Framework Directive, these water bodies were defined by the French water agency, dividing coastal waters into homogenous water bodies based on catchment areas (WFD, Directive 2000/60/EC). At each site, divers recorded the upper and lower limit of coralligenous concretions and conducted a survey stop every $10 \mathrm{~m}$ within the local bathymetric range. Each site thus contained one or several stations (Fig. 1).

A survey was performed at each station using a noninvasive method consisting of taking 30 photographic quadrates $(50 \mathrm{~cm} \times 50 \mathrm{~cm})$ along a $40-\mathrm{m}$ long horizontal transect, as described in Deter et al. (2012b). Photographic methods are commonly used for the analysis of coralligenous assemblages because they are nondestructive, save time underwater, are repeatable, and enable data archiving (Ferdeghini et al., 2000; Virgilio et al., 2006; Baldacconi and Corriero, 2009; Kipson et al., 2011; Deter et al., 2012a,b). All photographs at a given station were taken from the same orientation and depth, using a compass and a depth meter attached to the quadrate. Station depth varied from 17 to $90 \mathrm{~m}$, but more than $90 \%$ of all surveyed stations were between 30 and $70 \mathrm{~m}$ depth. Station distribution over depth is presented in Appendix S1. Stations were grouped into four depth categories for $\beta$-diversity analyses: $30-40$, 40-50, 50-60 and 60-70 m depth. Grouping stations in depth categories requires having a sufficient number of stations in each category. We thus excluded very shallow and very deep stations (i.e. four stations between 17 and $24 \mathrm{~m}$ and five stations between 75 and $90 \mathrm{~m}$ ), keeping 111 stations for further analysis.

Coralligenous assemblages were identified for each station on the basis of the photographs. Each picture was analysed by a single person using 64 random points via the coralligenous assemblages version of CPCe 4.1 (Kohler and Gill, 2006). This methodology was validated using part of the analysed dataset (Deter et al., 2012b). All points that indicated mobile organisms such as fish and crustaceans, as well as unidentifiable organisms, or abiotic substrate (rock, sand, rubble), were excluded from further analysis. This left more than $90 \%$ of the total points at each station. Finally, we identified coralligenous species according to the taxonomic nomenclatures of Guiry and Guiry (2013) and Rodriquez-Prieto et al. (2013). In some cases, identification was not possible at species level, but only at genus level. Hydrozoa and encrusting Bryozoa were not identified further and were classified as "Hydrozoa" and "Encrusting Bryozoa", each being considered a "species" for further analysis.

\subsection{Assessing facets of biodiversity}

We measured the three facets of coralligenous assemblages' biodiversity (i.e. taxonomic, functional and phylogenetic) at two spatial scales: (i) station level, i.e. $\alpha$-diversity and (ii) betweenstations level, i.e. $\beta$-diversity.

Assessing functional and phylogenetic diversity of assemblages requires accounting for the functional or phylogenetic distances between species present in the regional pool. Given that no a priori information exists on the functional role of coralligenous species and thus on the traits that are related to these functions, we considered a set of complementary traits describing the diverse facets of the coralligenous species niche (Appendix S2): morphology, reproduction mode, feeding strategy, defence and distribution traits. This functional database was built using information compiled from the existing bibliography (Hofrichter, 2004, 2005; RodriquezPrieto et al., 2013; http://doris.ffessm.fr/, Copyright 2012), with in some cases the addition of experts' judgement (Ballesteros, pers comm). We considered a large set of traits to avoid the risk of overestimating functional redundancy (Calba et al., 2014).

To avoid analysing inter-correlated functional traits, we computed the weighted Gower's distance between taxon pairs 
(Gower, 1971). We then performed a principal coordinate analysis (PCOA), which is the appropriate method for building functional space when functional traits are not continuous (Villéger et al., 2008). The PCoA was conducted using the functional distance matrix to build an 8-dimension functional space. The Euclidean distances between species in this functional space accurately reflect the initial Gower's distances based on trait values. The number of dimensions was selected according to the best indicator available to date (Appendix S3).

As for most studied species no sequence data was available, we estimated phylogenetic distances between species on the basis of species cladistics (Appendix S4). Phylogenetic distances between species were then estimated as the distance between a set of tips of the phylogenetic tree, calculated as the number of nodes separating each pair of species encountered in each community (Webb, 2000). Given that our measures of phylogenetic similarity are based only on the identified taxa within our communities, phylogenetic diversity does not reflect absolute species dissimilarities, as no complete dated phylogeny exists for all coralligenous species, but only relative ones, which does allow us to identify comparatively distinct communities within our study zone according to species relatedness, from similar to less similar ones (Webb, 2000).

Taxonomic, functional and phylogenetic $\alpha$-diversity were computed using the Rao's quadratic entropy $(Q)$ index. A range of different indicators exists to assess functional and phylogenetic diversity (see Cadotte et al., 2010; Mouillot et al., 2013). The Rao quadratic entropy index has the advantage of accounting for species abundances and of being adaptable for all three diversity facets (i.e. TD, FD, PD), which is essential to conduct diversity facets comparisons and explains its use in many studies similar to ours (e.g. Devictor et al., 2010b; Mouillot et al., 2011). The Rao quadratic entropy index combines species dissimilarity and species relative abundance (Pavoine et al., 2004; Ricotta, 2005; De Bello et al., 2010): $Q=\sum_{i=1}^{S} \sum_{j=1}^{S} d_{i j} p_{i} p_{j}$. In this case, $p$ stands for the estimate of relative coverage of each taxon at the station level, estimated as the number of points per identified species per station. The distance between species pairs $(d)$ for computing functional diversity (FD) was the distance in the 8-dimensions functional space after scaling values by dividing by their maximum. Similarly, phylogenetic diversity (PD) was computed considering $d_{i j}$ equal to the number of nodes among all pairs of species as a proxy for the phylogenetic distance between them and then divided by their maximum. Both functional and phylogenetic Rao's quadratic entropy was computed on the basis of ultrametric distance matrices. Taxonomic diversity (TD) was computed with $d_{i j}=1$ for all species pairs, which yields the Simpson diversity index (Ricotta, 2005).

Raw values of TD, FD and PD were transformed into equivalent number of species (Ricotta and Szeidl, 2009) by applying the following transformation: $Q_{\text {eqnbsp }}=1 /(1-Q)$. This transformation enables comparison of values among communities for the three facets. Low FD or PD values indicate that the dominant species within a community are functionally or phylogenetically close, whereas high FD or PD values indicate communities dominated by species that have distinct functional traits or from different lineages.

We assessed two types of $\beta$-diversity, horizontal and vertical. Our aim was to investigate how station dissimilarities vary according to their vertical or horizontal distances. A schematic representation of both vertical and horizontal $\beta$-diversities is given in Fig. 1. Vertical distances were estimated by subtracting station depths. Horizontal distances between each pair of stations were estimated as Euclidean distances using the latitude and longitude coordinates of each station. However, as this method makes no distinction between land or sea areas, we also considered horizontal distances by estimating the shortest distance from the sea among all pairs of stations, thus using a mask for land areas. Analyses were further conducted using both distances (see Appendix S5 for further details and results).

As horizontal structure can vary among depths, we considered four categories of sampled depths each spanning $10 \mathrm{~m}$ (also referred to as depth belts), ranging from 30 to $70 \mathrm{~m}$. We measured pairwise horizontal $\beta$-diversity as follows. We considered all stations within a specific depth belt, i.e. 36 stations within $40-50 \mathrm{~m}$ and 25 stations within each of the other three depth categories (30-40 m, 50-60 $\mathrm{m}$ and 60-70 m). We considered all pairs of stations within a given depth belt. We then estimated the mean $\alpha$ diversity for each pair of stations, based on Rao's index expressed as equivalent number of species (Ricotta and Szeidl, 2009; Villeger et al., 2012). $\gamma$-Diversity for each pair of stations was computed using the same index based on average taxa abundance in the two stations. Using the multiplicative framework built on the equivalent number of species, $\beta$-diversities were then estimated as the ratio between $\gamma$ and $\alpha$ diversities (Villeger et al., 2012). In addition to pairwise $\beta$-diversity, we also calculated overall $\beta$-diversity in each depth category as the ratio of overall $\gamma$ diversity of all stations situated within each depth category over the mean of their $\alpha$ diversity values.

For vertical $\beta$-diversity, we considered 7 geographical regions: 4 along the continental French Mediterranean coasts [western PACA with 11 stations, central PACA (16 stations), central-eastern PACA (18 stations) and eastern PACA (13 stations)], and 3 regions around Corsica island [northern Corsica with 18 stations, central Corsica (16 stations) and southern Corsica (15 stations)]. The aim of identifying geographical regions and depth belts is to focus on the coralligenous structure at a spatial scale that might correspond to the species biology and may be suitable for conservation purposes. A better approach would be to define regions on the basis of the actual connectivity level among assemblages, in order to more accurately reflect species dispersal capacities, but no adequate data exist so far for coralligenous species. Vertical $\beta$-diversity was not computed at the four stations located in the Languedoc Roussillon region because in this area coralligenous concretions only occur at low depth. We then estimated pairwise vertical $\beta$-diversity following the same procedure as with the horizontal $\beta$-diversity. We additionally calculated overall $\beta$-diversity per region as the ratio of overall $\gamma$-diversity of the region over mean $\alpha$-diversity of all stations situated within the same region.

Maps representing the spatial distribution of biodiversity facets were produced using kriging models which automatically fit a variogram to the data on which they are applied (Hiemstra et al., 2010). Kriging models were only used to produce maps and no further statistical analysis was conducted on them. All statistical tests concerning spatial structure and congruence were thus based only on observed data from the surveyed stations. Statistical analyses, plots and maps were produced with R(3.1.0) (R Development Core Team, 2014) using automap, ecodist, gdata, mgcv and vegan packages.

\subsection{Congruence among diversity facets}

To test congruence levels among the diversity facets, we used partial Mantel tests, with Pearson's correlation method. These tests calculate the spatial correlations between two dissimilarity matrices (e.g. TD and FD distance matrices), conditioned by a third matrix corresponding to the geographical distances between stations (Legendre and Legendre, 2012). Congruence was estimated for the three pairwise combinations between diversity facets, i.e. TD, FD and PD. In order to investigate whether and how congruence levels vary over depth, we considered congruence levels in three different cases, i.e. taking all stations ( $n=111$ stations) and dividing stations into two depth ranges: stations down to $50 \mathrm{~m}$ depth ( $n=59$ stations) vs deeper stations ( $n=52$ stations). 
Two supplementary analyses were used to test for significance and confirm that the observed levels of congruence among diversity facets were not driven by the dominance of a few taxa. We first considered null models where species were randomly sampled from the study pool, i.e. the pool of all species encountered in our study, according to their relative abundance (Calba et al., 2014). We repeated this random sampling procedure 1000 times, estimated the corresponding simulated TD, FD and PD and their congruence levels. We finally compared the observed levels of congruence with the distribution of the simulated data. This null modelling approach allows the validation of an ecological hypothesis, i.e. whether the observed congruence is different from what we should expect given the regional species pool, and is preferable to using the permutations procedure incorporated in the Mantel tests, which can in some cases be biased (Guillot and Rousset, 2013). In addition to that, to investigate relationships between FD and PD independently of the TD effect, we estimated net FD as the standardised residuals of the generalised additive model (gam) predicting FD from TD (Devictor et al., 2010b). The net PD was respectively computed from the gam (PD-TD). We finally estimated the congruence between net FD and net PD and compared it to the corresponding simulated data of these net indices. All plots of the relationships among diversity facets and the congruence levels between net FD and net PD are shown in Appendix S6. As the two approaches revealed similar results, we further estimate robustness of observed congruence levels using the null modelling approach.

\subsection{Diversity structure over space}

We investigated how $\alpha$ - and $\beta$-diversity were structured over space. We used gam models with depth, longitude and latitude as the explanatory variables for $\alpha$-diversity (Wood and Augustin, 2002). A spline effect was considered for all factors with three degrees of freedom (df) and the Fisher test was used to estimate the significance of explanatory variable trends. We considered separately horizontal and vertical $\beta$-diversities. We used generalised linear models ( $\mathrm{glm}$ ) to test for significant trends in $\beta$-diversity over vertical or horizontal distances for each of the regions or depth belts considered. For this specific analysis, our goal is not to identify the curve (linear or non-linear relationship) that best fits the data, in order to minimise residuals (as we did through gam for the alpha diversity), but to compare trends and identify zones where beta diversity increases or decreases over distance (in terms of depth or geographical terms) in higher rates than elsewhere. We additionally used overall $\beta$-diversities to compare dissimilarity levels among depth categories and regions.

\subsection{Assessing the efficacy of marine protected areas (MPAs) for coralligenous habitats}

In a recent review, Meinesz and Blanfuné (2015) thoroughly documented how to properly define protected zones in French Mediterranean in order to evaluate their development over the last 30 years. Following the European Community Habitat Directive, supplementary protection networks, such as the Natura 2000 sites, have been set up since 2009 , and are commonly considered in France as part of the marine protected areas network (Meinesz and Blanfuné, 2015). However, differences in management and regulation specificities among sites led the authors to consider as MPAs only those areas where specific restrictions on recreational and/or commercial fishing are imposed. Thus, only areas including specific no take zones, i.e. complete restriction of fishing, are considered. This is also consistent with the definition of MPAs in other European countries. We thus considered only MPA sites and excluded Natura 2000 sites from our analysis to be consistent with the definition of MPAs in Europe.
We estimated the proportion of the three facets of biodiversity found within the marine protected areas according to Mouillot et al. (2011). Firstly, we ranked coralligenous stations from the most to the least diverse for each facet of biodiversity. Secondly, we calculated the cumulative percentages of protected stations along these decreasing diversity gradients. Finally, we estimated the overall proportion of protected stations among all the stations.

We used the overall proportion of protected stations as a reference level to assess which facet of diversity is under- or over-represented in the protected areas. If MPAs are effective in protecting coralligenous habitats, we expected an overrepresentation of highly diverse stations located in protected areas. In contrast, an under-representation of highly diverse stations, i.e. less than the overall proportion within protected areas, would indicate low MPA efficacy (Mouillot et al., 2011).

Three distinct cases were considered based on (i) all stations, (ii) on stations down to $50 \mathrm{~m}$ depth and (iii) on stations more than 50 $\mathrm{m}$ deep. For all three cases, we assessed the cumulative proportion of taxonomic, functional or phylogenetic diversity present in MPAs.

\section{Results}

\subsection{Vertical and horizontal distribution of diversity facets}

Taxonomically richer communities were found in the central and eastern parts of the French Mediterranean coast and in the northern part of Corsica (Fig. 2(a)). Functionally richer communities were observed principally along the eastern French continental coast, whereas phylogenetically richer communities were mainly observed in Corsica and along the central continental coast (Fig. 2(b) and (c)). Mean $\alpha$-diversities ranged for TD from 1.9 to 13.9 , for FD from 1.2 to 2.1 and for PD from 1.3 to 5.7 in equivalent species numbers. Thus, FD was considerably lower than PD and TD at the station level. The concept of number of equivalent species implies that FD and PD could not be higher than TD. FD can only be equal to TD when all species have the same abundance and are maximally dissimilar. TD was thus more variable than FD and PD, since coralligenous species in each assemblage tend to have uneven abundances and be phylogenetically and functionally not highly dissimilar.

We further focused on variations in each facet to analyse their respective spatial patterns. Analysis of $\alpha$-diversity structure over space revealed that TD did not significantly vary over depth $(p=0.4$; Fig. 2(a)). However, both $\alpha$-FD $(F=7.8, p<0.01$; Fig. 2(b)) and $\alpha$ PD $(F=5.2, p=0.02$; Fig. 2(c)) significantly decreased with depth (Fig. 2). $\alpha$-FD and $\alpha$-PD increased with longitude ( $F=5.0, p=0.03$ and $F=7.1,<0.01$ respectively), with higher FD and PD in eastern regions. All three facets increased with latitude (TD: $F=4.3, p=0.02$; FD: $F=7.5, p<0.001$ and PD: $F=3.5, p=0.03$ ).

Mantel correlation analysis revealed that $\alpha$-FD and $\alpha$-TD were not more congruent than expected from the random model (Fig. 3(a)), and similar results were obtained when considering two categories, i.e. shallower than $50 \mathrm{~m}$ stations or deeper stations (Fig. 3(b) and (c)). Interestingly, while $\alpha$-PD was less congruent to TD than expected at random (Fig. 3(d)), congruence between FD and PD was higher than expected at random (Fig. 3(g)). Similar results were observed for deeper than $50 \mathrm{~m}$ stations (Fig. 3(f)-(i)), with FD being even more congruent to PD than previously observed, i.e. 0.84 vs 0.69 for all stations (Fig. 3(g) vs (i)). For shallower than $50 \mathrm{~m}$ stations, congruence was not significantly different from random distributions for any facet considered (Fig. 3(b), (e) and (h)). Congruence levels between FD and PD remained significantly higher than random even when retrieving the TD effect for FD and PD, i.e. net FD and net PD (see Appendix S6).

Vertical $\beta$-diversity mainly increased with depth for all three diversity facets (Fig. 4). Vertical taxonomic structure varied among 
(a)

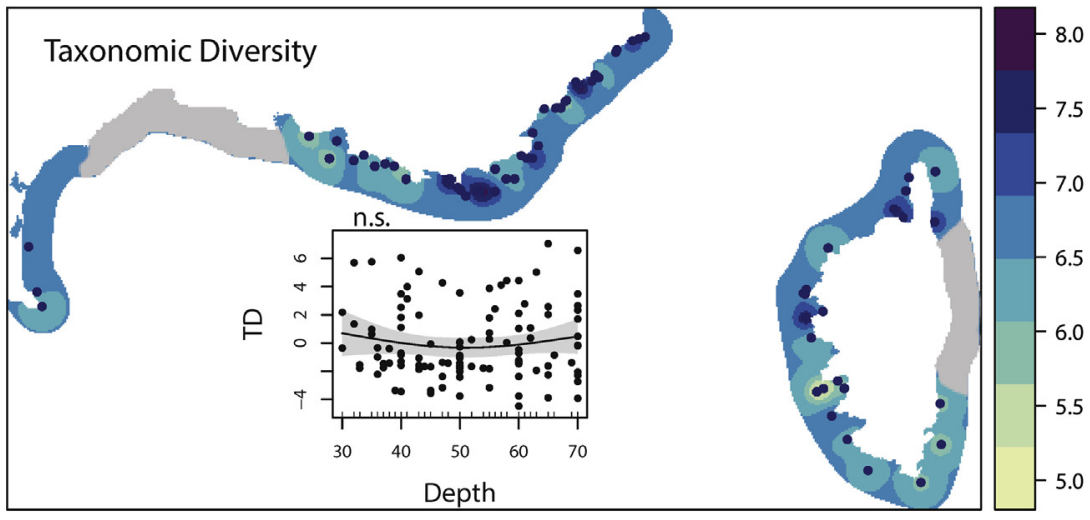

(b)

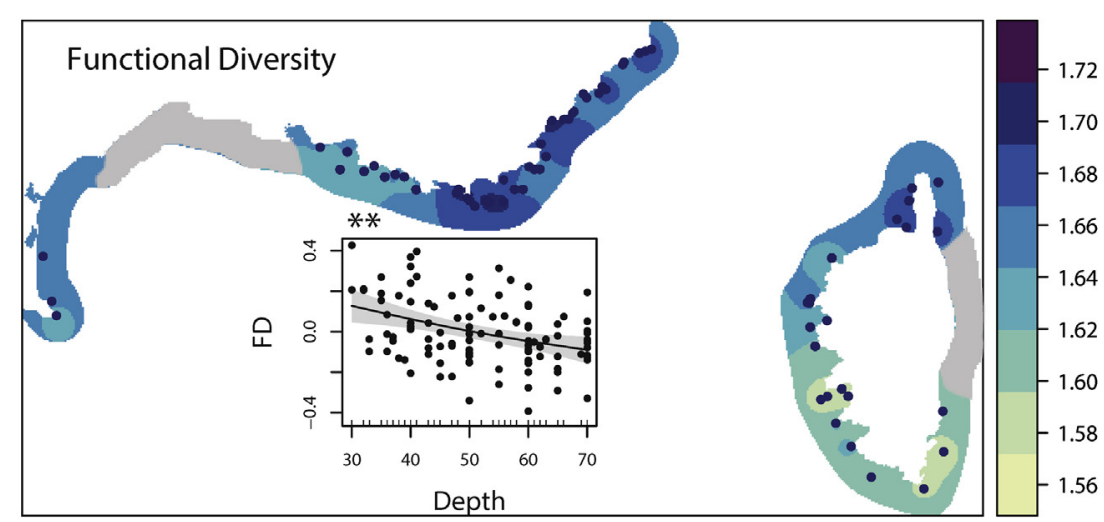

(c)

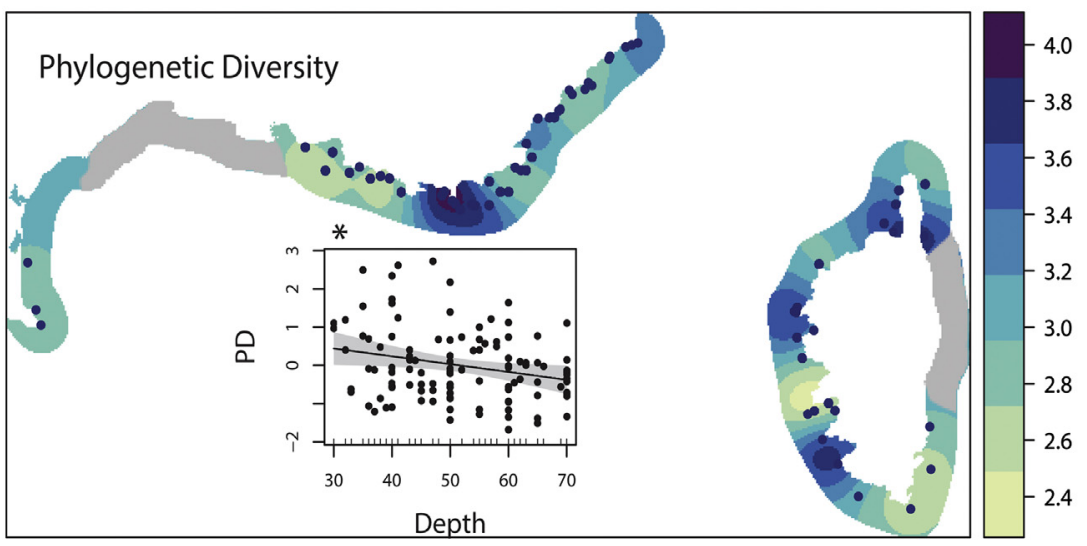

Fig. 2. Spatial distribution of the three $\alpha$ diversity facets: (a) TD, (b) FD and (c) PD. Low diversity levels are indicated in light yellow and high diversity levels in blue. Blue dots indicate the exact position of stations. Areas where no coralligenous assemblages are present are indicated in grey. $\alpha$ Diversity structure over depth is shown in plots. n.s. indicate non-significant trends, ${ }^{*}$ indicates significant $(p<0.05)$ and ${ }^{* *}$ highly significant trends $(p<0.01)$. (For interpretation of the references to color in this figure legend, the reader is referred to the web version of the article.)

regions, with eastern PACA $(t=6.71, p \ll 0.001)$ and northern Corsica $(t=6.43, p \ll 0.001)$ being the most vertically structured regions, i.e. where dissimilarities among stations strongly increase over depth (Fig. 4(a): EP \& NC). In central Corsica and central eastern PACA (Fig. 4(a): CC \& CEP), taxonomic $\beta$-diversity increased with depth $(t=3.03, p<0.01$ and $t=5.20, p<0.001$ respectively), but less than in eastern PACA. No trends in taxonomic $\beta$-diversity were observed over depth within western PACA (WP: $p=0.8$ ) and southern Corsica (SC: $p=0.6$ ). Vertical functional and phylogenetic $\beta$-diversities showed similar patterns in all regions (Fig. 4(b) for PD trends and Appendix S7 for FD trends). Functional and phylogenetic $\beta$-diversities mostly increased with depth in eastern PACA ( $t=9.35, p<0.001$ and $t=10.94, p<0.001$ respectively), in central eastern PACA $(t=6.65, p<0.001$ and $t=7.51, p<0.001$ for FD and PD respectively) and in northern Corsica ( $t=4.19, p<0.001$ and $t=4.83, p<0.001$ respectively). Non-significant trends were obtained in southern Corsica, western and central PACA regions for both functional $\beta$-diversity ( $p=0.9, p=1, p=0.2$ respectively) and phylogenetic $\beta$-diversity $(p=0.3, p=0.1, p=1)$.

Overall vertical $\beta$-diversities ranged between 1.51 and 3.09 for taxonomic facet, from 1.05 to 1.20 for functional facet and between 1.10 and 1.78 for phylogenetic facet, with the highest overall $\beta$-diversities being observed in central eastern PACA and the lowest in western PACA, for all three facets of diversity (Fig. 5(a)). Functional $\beta$-diversity was lower than phylogenetic $\beta$-diversity and even lower than taxonomic $\beta$-diversity for both vertical and 

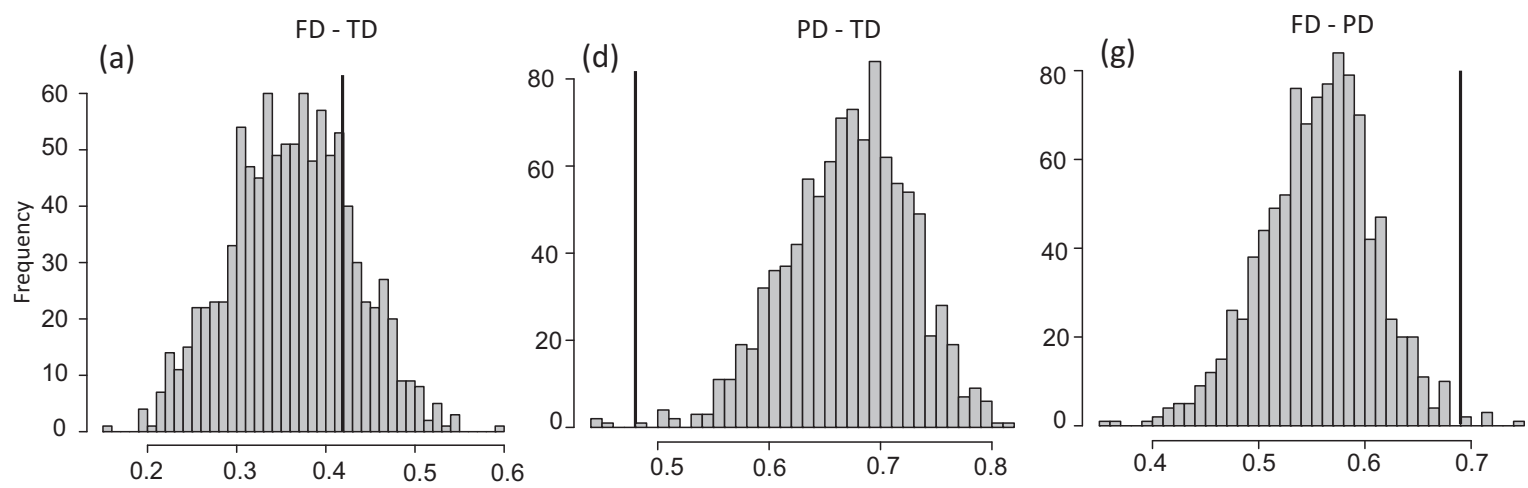

All stations
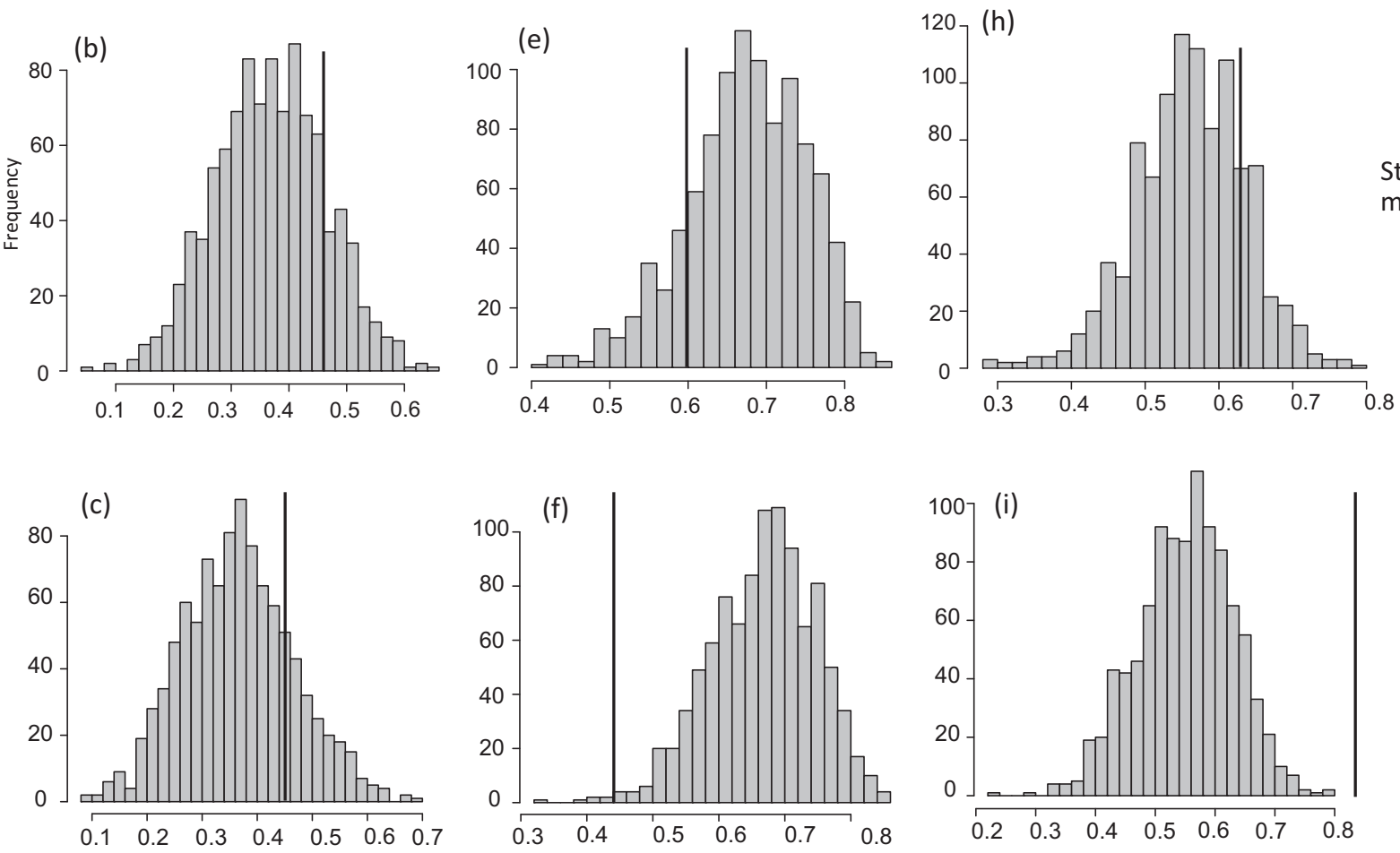

Stations $>50$

m depth

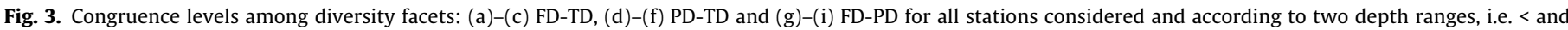

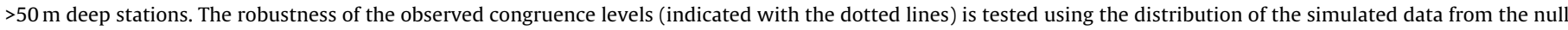
models (shown as grey bars).

horizontal scales (Fig. 5(a)). Overall horizontal $\beta$-diversity ranged for TD from 2.31 to 2.53 , for FD from 1.13 to 1.16 and for PD from 1.39 to 1.63 , with higher overall $\beta$-diversity being observed in low depth belts $(50-70 \mathrm{~m})$ and lower overall $\beta$-diversity in more shallow depth belts (30-50 m), for all three facets of biodiversity (Fig. 5(b)).

Pairwise horizontal taxonomic, functional and phylogenetic $\beta$-diversity increased with distance for all four depth belts $(p<0.001$; Appendix S5). However, horizontal distance between stations explained a small part of the $\beta$-diversity of the three facets, i.e. $\beta$-TD, $\beta$-FD and $\beta$-PD, i.e. $R^{2}$ of $\beta$-diversity over horizontal distances varied from 0.01 to 0.16 , when considering the Euclidean distances between stations. Similar results were obtained, when considering sea distances between stations. All trends of $\beta$-TD, $\beta$-FD and $\beta$-PD over horizontal distances, using both approaches to estimate geographical distances, can be seen in Appendix S5.

\subsection{Conservation efficacy}

All three facets of diversity are globally under-represented within MPAs which include specific no take zones (Fig. 6). Stations with the highest diversity levels were generally not in protected areas. Separating stations into two depth categories revealed that MPAs seem to be better at protecting stations down to $50 \mathrm{~m}$ depth, but do much worse in deeper stations (from 50 to $70 \mathrm{~m}$ ) (Fig. 6(b) vs (c)). The overall proportion of protected diversity for all stations was around $13 \%$, rising to $17 \%$ for stations down to $50 \mathrm{~m}$ depth. Conservation efficacy was particularly low for depths below $50 \mathrm{~m}$, as almost one third of the stations of this depth category - corresponding to the 15-17 richest stations according to the diversity facet considered - are not located inside MPAs, and only $8 \%$ of the stations of this depth category were located within protected areas (Fig. 6(c)).

\section{Discussion}

\subsection{Multi-facet diversity of coralligenous assemblages}

We have revealed that functional diversity was generally lower than phylogenetic diversity and even lower than taxonomic diversity, indicating the presence of a few, abundant, functionally similar species within most stations. Moreover, TD was not significantly congruent to FD but it was significantly less congruent to PD 
(a)
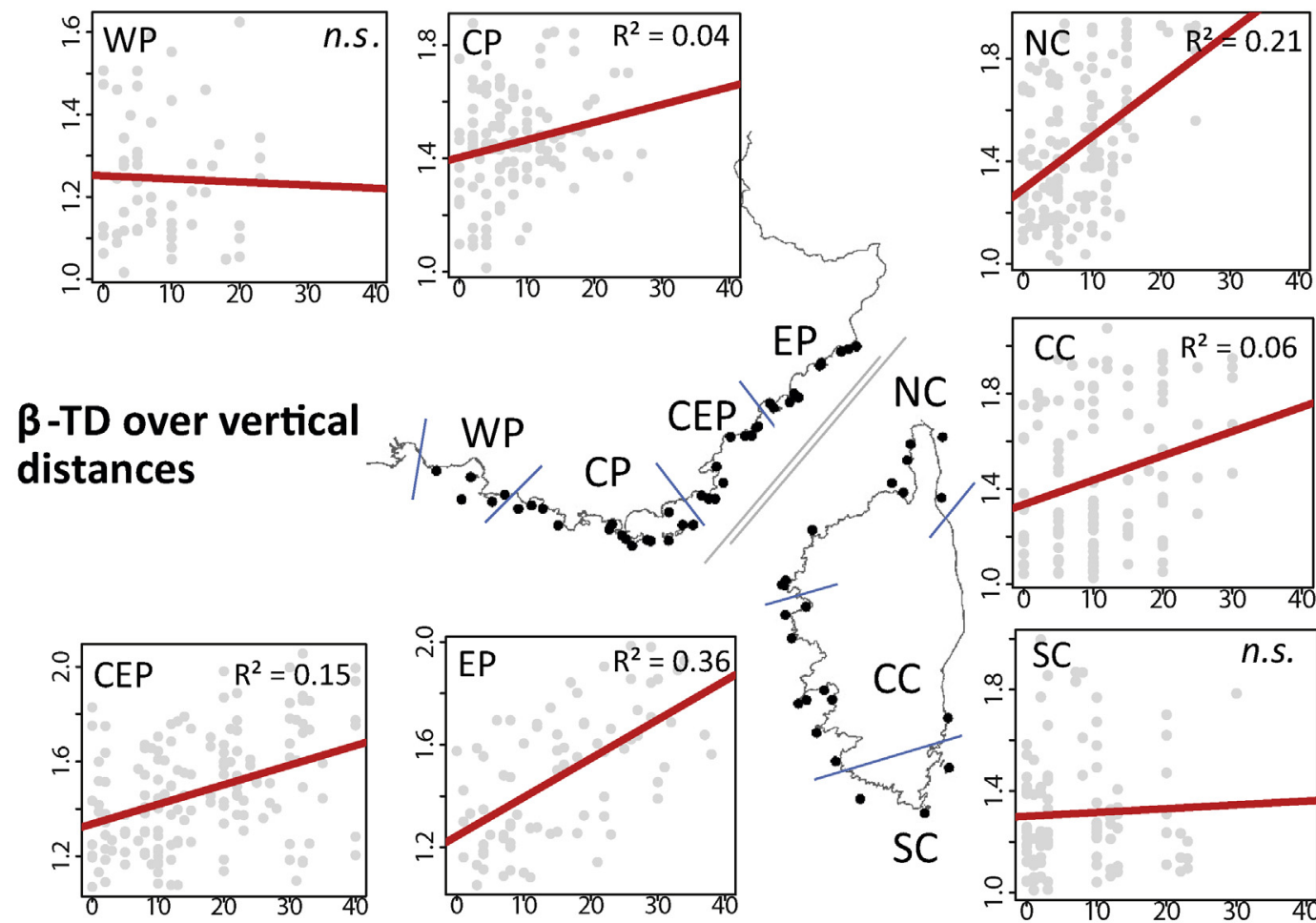

(b)
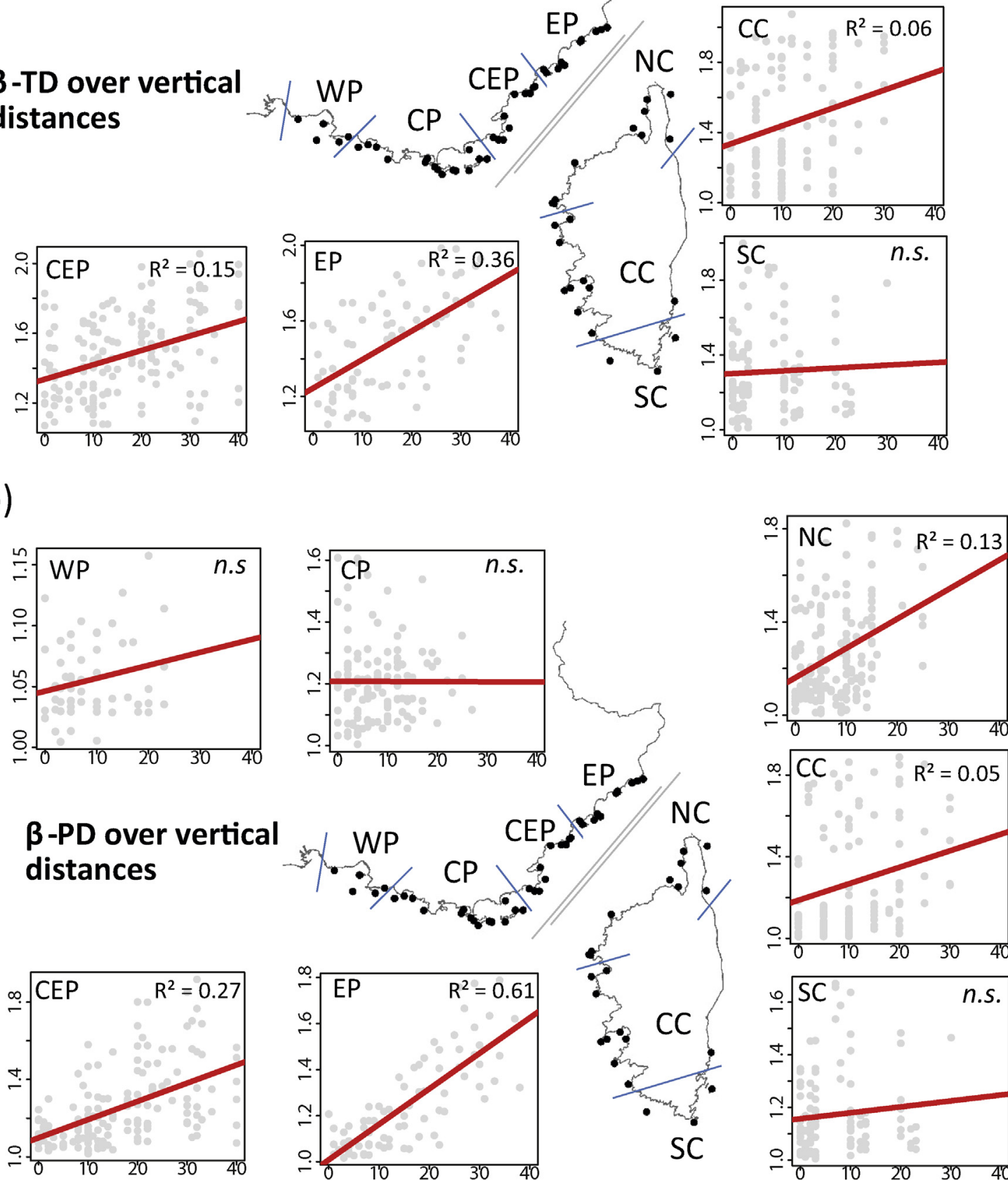

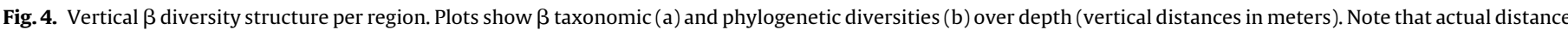

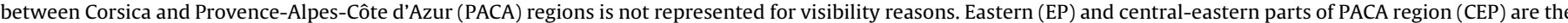

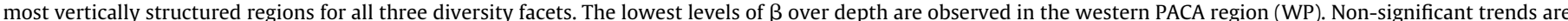
indicated as n.s.

than expected at random. This indicates that TD and PD patterns provide complementary information about coralligenous assemblages. More interestingly, FD and PD were highly congruent to each other, with similar spatial distribution patterns over vertical and horizontal axes. Finally, congruence between functional and phylogenetic diversities increased for stations deeper than $50 \mathrm{~m}$, where taxonomic diversity was not congruent to either functional or phylogenetic diversities. 
(a) Vertical overall $\beta$ diversity per region

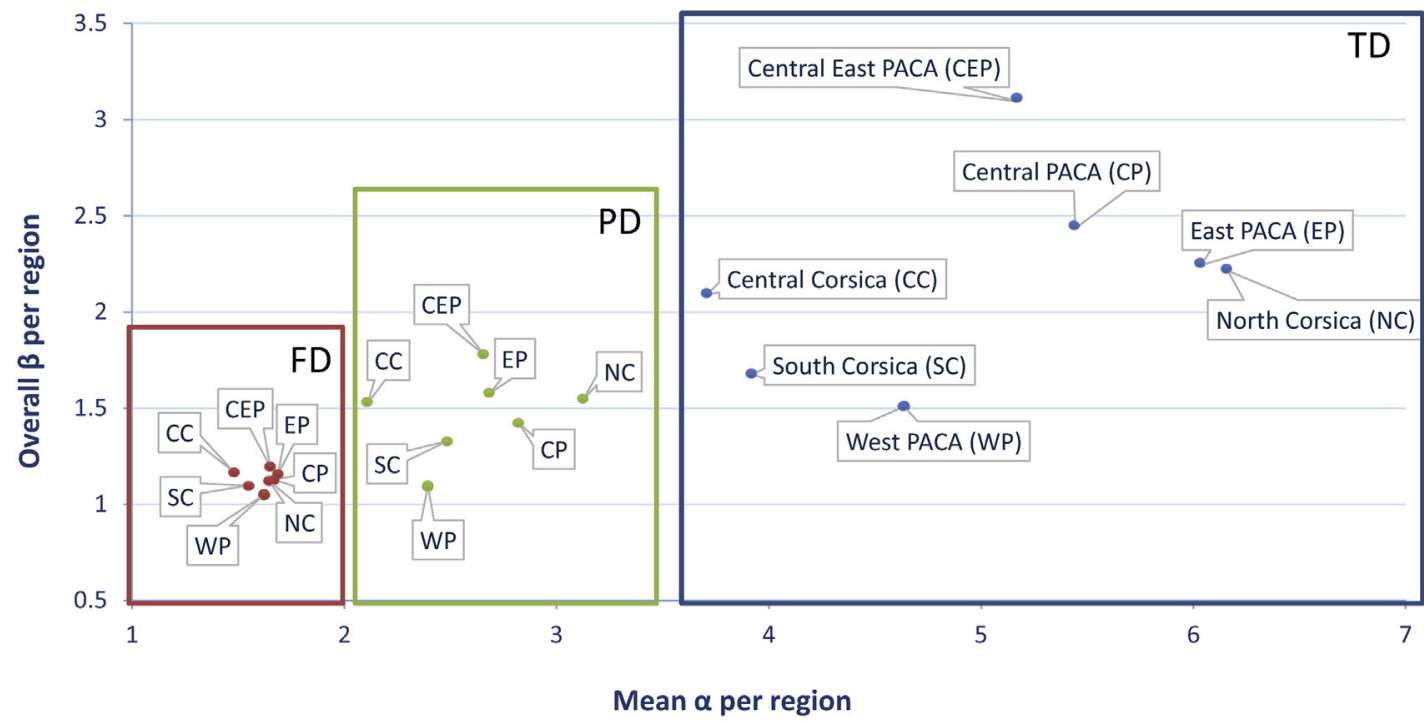

(b)

Horizontal overall $\beta$ diversity per depth belt

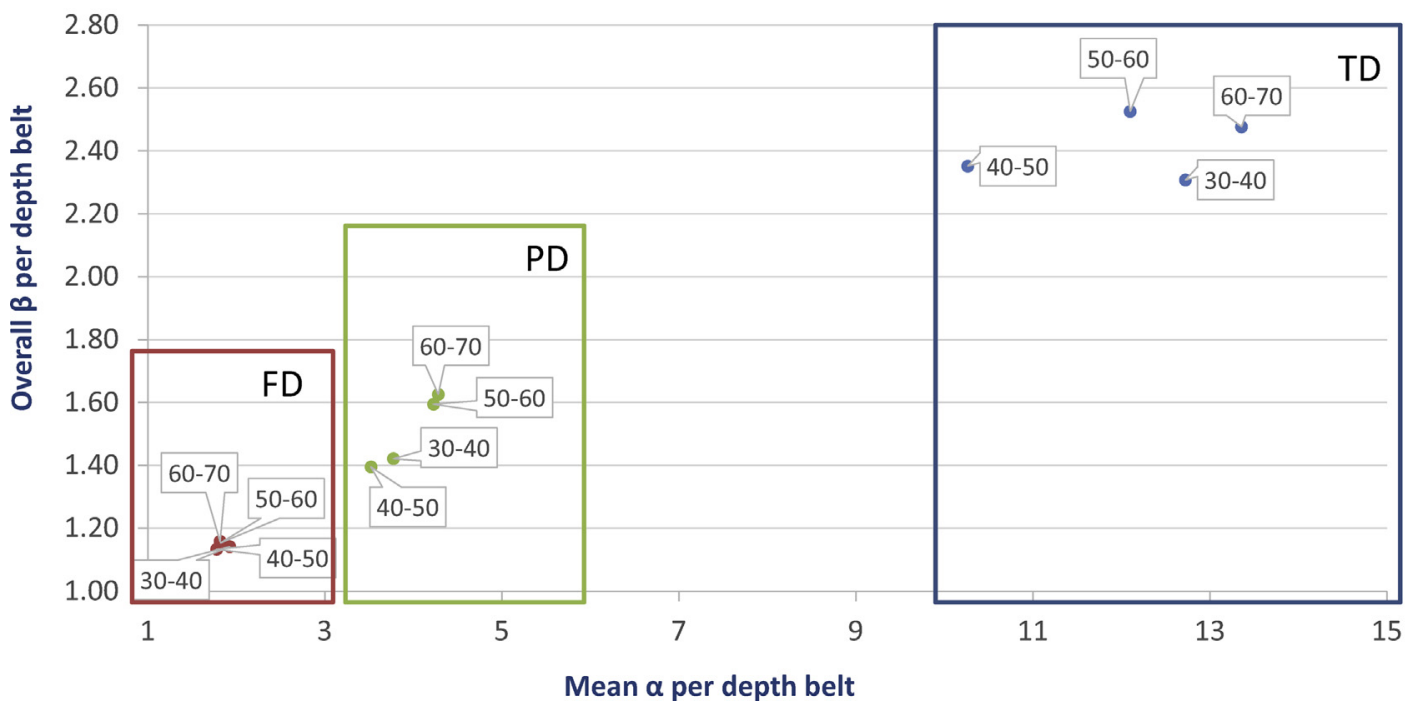

Fig. 5. Overall vertical and horizontal $\beta$ diversities. Dissimilarities per region (a) and per depth belt (b) are plotted over the corresponding mean $\alpha$ diversities.

The use of phylogenetic diversity as a proxy for functional diversity (Cadotte et al., 2008) has been debated and several recent studies offer evidence of a significant lack of congruence between the two facets (Devictor et al., 2010b; Mouillot et al., 2011; Safi et al., 2011). In our case, the high congruence between functional and phylogenetic diversity might be driven by niche conservatism. In old lineages, environmental tolerances are restricted, leading to a phylogenetic clustering (Swenson et al., 2006; Swenson, 2011). On the other hand, if species divergence is more recent, we may expect trait overdispersion (Ndiribe et al., 2013). However, when old and more recent lineages are encountered within communities, as typically occurs in coralligenous assemblages, traits' phylogenetic signal may be masked by lineage-specific differences in trait evolution (Smith and Donoghue, 2008; Ndiribe et al., 2013). Given our results, i.e. low phylogenetic and functional diversities and high congruence between them, we assume that functional and phylogenetic clustering occurs in coralligenous assemblages, making them even more vulnerable to climate change or human disturbances. Species sharing similar adaptations and restricted environmental tolerance are expected to respond similarly to increasing disturbance risks, and thus even small future changes can have a detrimental impact on ecosystem functioning (Mouquet et al., 2012; Srivastava et al., 2012).

However, the exact functional role of coralligenous habitats in the Mediterranean basin has not yet been clarified (Georgiadis et al., 2009). Previous studies indicated that coralligenous species strongly structure their environment by capturing particulate organic matter sedimentation, creating niches and improving the food availability for a number of species, such queen scallops, soft clams, sea urchins, starfish and gadoids (Kamenos et al., 2004; Lloret et al., 2007). Yet the specific traits which relate to the ecosystem functioning have not yet been clearly identified for the coralligenous concretions, thus making the estimation of these ecosystem engineers' functional diversity particularly challenging. Here, we estimated functional diversity on the basis of a set of complementary species characteristics describing their morphology, reproduction and ecology. This set is similar to the one recently used to characterise functional diversity of fossil and 

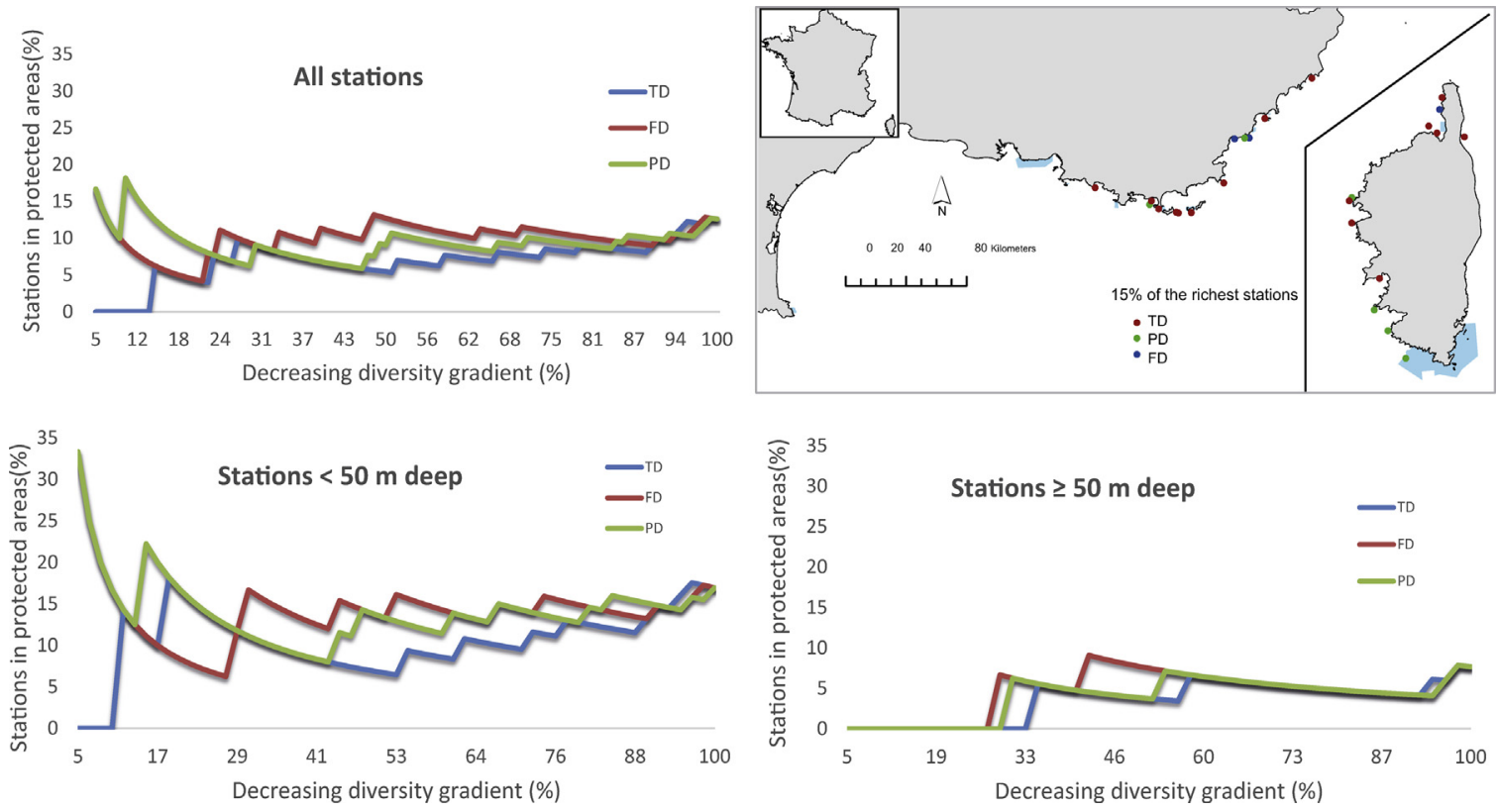

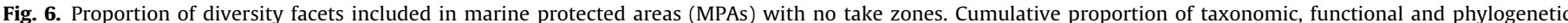

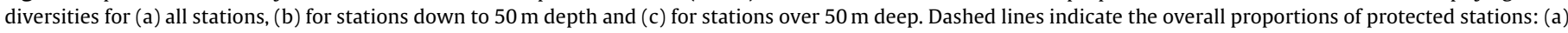

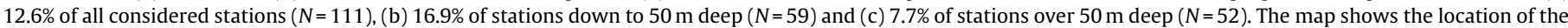

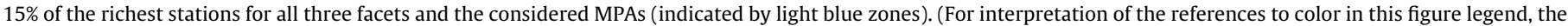
reader is referred to the web version of the article.)

present benthic assemblages (Villéger et al., 2011). Future studies on coralligenous ecosystems could make it possible to better distinguish particular aspects of ecosystem functioning such as resistance to invasion or traits linked to the flow of matter and energy within the ecosystem, to enable more interpretable estimations of functional diversity.

While incredibly diverse, the coralligenous assemblages remain largely inaccessible to systematic sampling. We preferred to use a non-invasive technique, based on photos, which is recommended for underwater ecological systems (UNEP-MAP-RAC/SPA, 2011) and widely used (Balata et al., 2005; Baldacconi and Corriero, 2009; Kipson et al., 2011; Deter et al., 2012a,b). However, this approach does not allow identification of all individuals at the species level (particularly for cryptic species). In our analysis, we adopted a conservative approach by keeping identifications at the genus level or higher groups, instead of risking overestimation of richness in cases of impossible identification at the species level. The number of species is thus underestimated in all stations for both alpha and beta diversity components, but this bias is common to all stations, thus allowing comparisons among stations, which is the main aim of the present work.

In the absence of adequate molecular information for coralligenous species, we used cladistics to calculate phylogenetic diversity. Other methods, based on dated phylogenies, have also been developed and used to estimate phylogenetic diversity when studying community structure and ecosystem stability (Cadotte et al., 2010, 2012; Flynn et al., 2011). Molecular approaches are more accurate and should be preferred when needing to estimate phylogenetic distances (Pavoine and Bonsall, 2011), but require that every single species should be adequately sequenced, which is not feasible at present for coralligenous communities. Recent evidence showed that plants phylogenetic diversity estimated by undated taxonomic hierarchies, such as the one used here, is closely related to the diversity obtained by dated phylogenies (Ricotta et al., 2012). This should be further verified in the future for other organisms. Inferring large and reliable phylogenetic trees still remains a challenge, but suitable tools are increasingly becoming available to conservation biologists (Roquet et al., 2013). Future studies on coralligenous phylogenetic diversity should thus consider more appropriate methods, considering supertree and supermatrix approaches (Bininda-Emonds et al., 2002; McMahon and Sanderson, 2006; Roquet et al., 2013). Taking into account the ecological importance of coralligenous habitats, and despite all the above limitations related to PD and FD estimations, our study provides the first multi-facet distribution analysis of coralligenous assemblages worldwide. Further research on molecular sequencing and studies on particular functions of coralligenous species can help refine knowledge of the phylogenetic and functional diversity of this rich ecosystem.

\subsection{Vertical and horizontal structure of coralligenous assemblages}

At local scale ( $\alpha$-diversity), depth was the main axis structuring functional and phylogenetic diversities, with shallow stations being on average richer than deep stations. No significant variation was observed over depth for taxonomic diversity. A slight horizontal structure was observed for all facets of diversity, with richer communities being located in the north-eastern part of our study area, i.e. eastern PACA and northern Corsica. In marine ecosystems, species' functional roles and evolutionary history are driven by spatially distributed environmental conditions, such as light and nutrient availability (Thingstad et al., 2005; Elser et al., 2007). Typically, communities sharing high water clarity and light availability conditions will be characterised, in shallower waters, by higher cover of erect Udoteaceae (Flabellia petiolata) and Mesophyllum alternans (Balata et al., 2006; Ballesteros, 2006; Piazzi and Balata, 2011). These taxa are replaced in deeper waters by encrusting and laminar Rhodophyta (Ballesteros, 2006), or Porifera at greater depths (Deter et al., 2012a). Such changes in assemblage composition, resulting from the replacement of one species (or group of species) by another, may often not be perceived in terms of taxonomic diversity (Devictor et al., 2010a). Functional and phylogenetic information on community composition takes into account 
this turnover, and is therefore the key to establishing the spatial variations of biological diversity (Mouquet et al., 2012).

Taxonomic, functional and phylogenetic dissimilarities among assemblages ( $\beta$-diversity) increased with depth mainly in the central and eastern Provence-Alpes-Côte d'Azur (PACA) region and in northern Corsica, where the vertical gradient was high. In eastern Provence (EP), conditions along the water column favour the existence of coralligenous concretions in various depth belts. However the composition of coralligenous concretions varies among depths, with species from shallow assemblages being phylogenetically distinct (green, brown and red algae but also bryozoans, gorgonians and sponges) than species forming deeper concretions (many sponges associated with red algae). The presence of such dominant phylogenetically distinct species explains why beta phylogenetic diversity increases over depth mostly in eastern Provence.

We observed no vertical structure in other regions, in western PACA and southern Corsica. In regions where suspended matter, pollution or turbulence decreases water transparency, as in the western part of Provence (near Marseille) for example, water specific conditions become unfavourable to coralligenous species in relatively shallow waters (20-30 m deep) and the shift between shallow, more light-requiring to deep sciaphilic macroalgal communities may occur at a shallower depth than usual (Balata et al., 2006). Moreover, in human impacted zones, species that are sensitive to disturbance may decrease, while more generalist species become more dominant (Balata et al., 2007a,b). These effects can result in low dissimilarities among communities and may explain why the $\beta$ diversity of all three facets remained very low and invariable over different depths in western PACA. Several sites in Corsica may reflect the opposite case scenario, where favourable water conditions along a wide depth gradient, permit coralligenous concretions to be rich in species but their composition varies less over depth, as high water transparency results in more homogeneous environmental conditions, whatever the depth. Thus $\beta$ diversity trends can be less marked over depth, even in good quality habitats.

We observed little evidence of the coralligenous structure over the horizontal axis as horizontal distances between stations explained a small part of the dissimilarities between them in all three $\beta$-diversity facets, i.e. TD, FD and PD. Comparatively higher horizontal $\beta$-diversity was observed for intermediate and deep stations, i.e. 50-70 $\mathrm{m}$ deep. This depth range represents the vast majority of the analysed stations, including areas from the PACA and the Corsica regions. Water characteristics and transparency are expected to vary among regions, especially between the western and central PACA and the Corsica stations. Terrestrial inputs in deltaic areas, such as the Rhone river, should contribute to inter-region differences. The Rhone delta is an important source of particulate organic matter sedimentation, with particular peaks at intermediate depths (30-50 m) and the lowest input at 70-100 m depth (Darnaude et al., 2004). Such sedimentation inputs have an impact on marine macrobenthos activity (Darnaude et al., 2004), which may be reflected in several of the PACA stations' coralligenous composition.

In our approach, we used geographical and depth distances as a proxy for the environmental conditions that vary over space. However, as previously mentioned, the water's physico-chemical characteristics and inter-species interactions can modify vertical distribution of the coralligenous species, resulting in different community compositions at similar depths (Airoldi, 2003; Dauer et al., 2008; Piazzi and Balata, 2011). Thus, a more specific analysis of spatial patterns in $\beta$-diversity related to key environmental and human pressure variables, such as temperature, turbidity and pollution, and taking into account various vertical and horizontal distances, should shed light on the mechanisms that drive diversity patterns in coralligenous habitats. This should result in more effective conservation measures to preserve biodiversity at both local and regional scales. Nevertheless, regardless of the limitations of using depth as a proxy, our analysis provided evidence of coralligenous $\alpha$ - and $\beta$ diversity vertical structure, which should be further considered for setting future conservation goals.

\subsection{Conservation implications}

New options for marine conservation may result from multifaceted three-dimensional analyses. Vertical and horizontal variability can provide useful input for conservation planning, indicating whether the most effective approach to conservation is local and/or regional (Baselga, 2010). If conservation effort focuses on preserving local diversities, restrictions should be imposed with increasing intensity from shallow to deeper water levels. However, this local approach could fail to protect species characteristic of deeper habitats (such as sponge species, for example). In contrast to the more classical approach of marine reserves that focus on protecting specific sites vertically, horizontal $\beta$-diversity could be favoured by implementing conservation measures that take into account depth range. In some areas, more effective preservation of biotic dissimilarities could be achieved by regulating human activities at certain depths, thus adding a horizontal type of reserve to the existing vertical ones.

Both conservation efforts and disturbance resulting from human activities are depth dependent. While reviewing the development of MPAs over the last 30 years in the French Mediterranean, one realises that while conservation planning initially focused on rather shallow waters habitats, more recent efforts are contributing to the protection of deeper than $50 \mathrm{~m}$ ecosystems (Meinesz and Blanfuné, 2015). However, the distribution of the protected areas by depth range remains partial and inappropriate (Meinesz and Blanfuné, 2015) and seems insufficient to protect coralligenous habitats. In addition to the MPAs, Natura 2000 sites and European Union regulations specifically include coralligenous formations among the list of habitats to be protected. However, human activities and in particular commercial fishing interests are in conflict with conservation goals. Since coralligenous communities compose the habitat of several species of fish, mechanistic destruction due to fishing remains one of the main threats for coralligenous habitats in the Mediterranean region (Georgiadis et al., 2009). The efficacy of future conservation measures will thus largely depend on the selection of regions and depth belts to preserve.

Zones deeper than $50 \mathrm{~m}$ may continue to be less impacted by human disturbances than shallow waters, and deeper coralligenous concretions can act as refuge areas at least for some species. It would be of interest to test whether the deep reef refuge hypothesis (Bongaerts et al., 2011; Serrano et al., 2014) - according to which shallow communities can profit from deeper ones following disturbance, by using them as local recruitment sources - can be applied to the coralligenous habitats. Future research on larvae vertical and horizontal migration would be needed to clarify these aspects. This would additionally shed light on connectivity issues that might explain the observed diversity patterns of coralligenous concretions and become critical to the future connectivity of marine protected areas (Andrello et al., 2015).

\section{Conclusions}

Given the important ecological role of coralligenous habitats, providing habitat and filter functions for several microorganisms and fish species, and their low resilience to disturbance (Georgiadis et al., 2009), Mediterranean marine conservation needs to be designed and implemented on the basis of spatially adaptive methods able to monitor the three-dimensional spatial variability of diversity. We suggest that using taxonomic diversity alone may 
be misleading, and that additional information, at least on phylogenetic diversity, is required to properly set future conservation goals and enable conservationists to apprehend the spatial variations of community composition (Mouquet et al., 2012). There should, moreover, be a particular focus on ecosystem verticality, which may help preserve dissimilarities among coralligenous concretions. Local conservation measures should be embedded within a larger scale strategy able to identify areas and depth belts that maintain higher diversity levels. Although three-dimensional analyses are complex and constitute a challenge for conservationists and biogeographers, they should be further considered in order to encapsulate the different facets of biotic diversity and propose adequate ways of preserving biodiversity at different scales.

\section{Acknowledgements}

This work was funded by the Agence de l'eau RMC, Andromède Océanologie, ISEM, UM2 and OSU OREME. Field data come from the monitoring programme RECOR (www.observatoire-mer.fr/en). Florian Holon was supported by a PhD grant from LabEX CeMeb and Andromède Océanologie. We thank Enrike Ballesteros for his help with identification and with completion of the functional database. We thank Marjorie Sweetko and Michael Paul for revising the English of the manuscript. We thank Vincent Devictor for his help and advice on modelling issues. We also thank Wilfried Thuiller for his helpful comments on a previous version of the paper.

\section{References}

Abdulla, A., Gomei, M., Hyrenbach, D., Notarbartolo-di-sciara, G., 2009. Challenges facing a network of representative marine protected areas in the Mediterranean: prioritizing the protection of underrepresented habitats. CES J. Mar. Sci. 66, $22-28$.

Airoldi, L., 2003. The effects of sedimentation on rocky coast assemblages. Oceanogr. Mar. Biol. 41, 161-236.

Andrello, M., Mouillot, D., Somot, S., Thuiller, W., Manel, S., 2015. Additive effects of climate change on connectivity between marine protected areas and larval supply to fished areas. Divers. Distrib. 21, 139-150.

Balata, D., Acunto, S., Cinelli, F., 2006. Spatio-temporal variability and vertical distribution of a low rocky subtidal assemblage in the north-west Mediterranean. Estuar. Coast. Shelf Sci. 67, 553-561.

Balata, D., Piazzi, L., Benedetti-Cecchi, L., 2007a. Sediment disturbance and loss of beta diversity on subtidal rocky reefs. Ecology 88, 2455-2461.

Balata, D., Piazzi, L., Cecchi, E., Cinelli, F., 2005. Variability of Mediterranean coralligenous assemblages subject to local variation in sediment deposition. Mar. Environ. Res. 60, 403-421.

Balata, D., Piazzi, L., Cinelli, F., 2007b. Increase of sedimentation in a subtidal system: effects on the structure and diversity of macroalgal assemblages. J. Exp. Mar. Biol. Ecol. 351, 73-82.

Baldacconi, R., Corriero, G., 2009. Effects of the spread of the alga Caulerpa racemosa var. cylindracea on the sponge assemblage from coralligenous concretions of the Apulian coast (Ionian Sea, Italy). Mar. Ecol. 30, 337-345.

Ballesteros, E., 2006. Mediterranean coralligenous assemblages: a synthesis of present knowledge. Oceanogr. Mar. Biol. Annu. Rev. 44, 123-195.

Baselga, A., 2010. Partitioning the turnover and nestedness components of beta diversity. Glob. Ecol. Biogeogr. 19, 134-143.

De Bello, F., Lavergne, S., Meynard, C.N., Lepš, J., Thuiller, W., 2010. The partitioning of diversity: showing Theseus a way out of the labyrinth. J. Veg. Sci. 21, 992-1000.

Bianchi, N., Morri, C., 2000. Marine biodiversity of the Mediterranean Sea: situation problems and prospects for future research. Mar. Pollut. Bull. 40, 367-376.

Bininda-Emonds, O.R.P., Gittleman, J.L., Steel, M.A., 2002. The (super)tree of life: procedures, problems, and prospects. Annu. Rev. Ecol. Syst. 33, 265-289.

Bonecker, S.L.C., de Araujo, A.V., de Carvalho, P.F., Dias, C.D.O., Fernandes, L.F.L., Migotto, A.E., de Oliveira, O.M.P., 2014. Horizontal and vertical distribution of mesozooplankton species richness and composition down to $2,300 \mathrm{~m}$ in the southwest Atlantic Ocean. Zoologia 31, 445-462.

Bongaerts, P., Sampayo, E.M., Bridge, T.C.L., Ridgway, T., Vermeulen, F., Englebert, N., Webster, J.M., Hoegh-Guldberg, O., 2011. Symbiodinium diversity in mesophotic coral communities on the Great Barrier Reef: a first assessment. Mar. Ecol. Prog. Ser. 439, 117-126

Cadotte, M.W., Cardinale, B.J., Oakley, T.H., 2008. Evolutionary history and the effect of biodiversity on plant productivity. Proc. Natl. Acad. Sci. U. S. A. 105 $17012-17017$

Cadotte, M.W., Dinnage, R., Tilman, D., 2012. Phylogenetic diversity promotes ecosystem stability. Ecology 93, S223-S233.

Cadotte, M.W., Jonathan Davies, T., Regetz, J., Kembel, S.W., Cleland, E., Oakley, T.H., 2010. Phylogenetic diversity metrics for ecological communities: integrating species richness, abundance and evolutionary history. Ecol. Lett. 13, 96-105.

Calba, S., Maris, V., Devictor, V., 2014. Measuring and explaining large-scale distribution of functional and phylogenetic diversity in birds: separating ecological drivers from methodological choices. Glob. Ecol. Biogeogr. 23, 669-678.

Cartes, J.E., Maynou, F., Sardà, F., Company, J.B., Lloris, D., de Ciències, I., 2004. The Mediterranean deep-sea ecosystems: an overview of their diversity, structure, functioning and anthropogenic impacts. In: Tudela, S., Simard, F. (Eds.), The Mediterranean Deep-Sea Ecosystems: An Overview of Their Diversity, Structure, Functioning and Anthropogenic Impacts, with a Proposal for Their Conservation. IUCN, Malaga, pp. 1-64.

Claudet, J., Pelletier, D., 2004. Marine protected areas and artificial reefs: a review of the interactions between management and scientific studies. Aquat. Living Resour. 17, 129-138.

Claudet, J., Pelletier, D., Jouvenel, J.-Y., Bachet, F., Galzin, R., 2006. Assessing the effects of marine protected area (MPA) on a reef fish assemblage in a northwestern Mediterranean marine reserve: identifying community-based indicators. Biol. Conserv. 130, 349-369.

Coll, M., Piroddi, C., Albouy, C., Lasram, F.B.R., Cheung, W.W.L., Christensen, V., Karpouzi, V.S., Guilhaumon, F.F., Mouillot, D., Paleczny, M., Palomares, M.L., Steenbeek, J., Trujillo, P., Watson, R., Pauly, D., Ben, F., Lasram, R., Ben Rais Lasram, F., 2012. The Mediterranean Sea under siege: spatial overlap between marine biodiversity, cumulative threats and marine reserves. Glob. Ecol. Biogeogr. 21, 465-480.

Darnaude, A., Salen-Picard, C., Harmelin-Vivien, M., 2004. Depth variation in terrestrial particulate organic matter exploitation by marine coastal benthic communities off the Rhone River delta (NW Mediterranean). Mar. Ecol. Prog. Ser. 275, 47-57.

Dauer, D.M., Llansó, R.J., Lane, M.F., 2008. Depth-related patterns in benthic community condition along an estuarine gradient in Chesapeake Bay, USA. Ecol. Indic. 8, 417-424.

Deter, J., Descamp, P., Ballesta, L., Boissery, P., Holon, F., 2012a. A preliminary study toward an index based on coralligenous assemblages for the ecological status assessment of Mediterranean French coastal waters. Ecol. Indic. 20, 345-352.

Deter, J., Descamp, P., Boissery, P., Ballesta, L., Holon, F., 2012b. A rapid photographic method detects depth gradient in coralligenous assemblages. J. Exp. Mar. Biol. Ecol. 418-419, 75-82.

Devictor, V., Clavel, J., Julliard, R., Lavergne, S., Mouillot, D., Thuiller, W., Venail, P., Villéger, S., Mouquet, N., 2010a. Defining and measuring ecological specialization. J. Appl. Ecol. 47, 15-25.

Devictor, V., Mouillot, D., Meynard, C., Jiguet, F., Thuiller, W., Mouquet, N., 2010b. Spatial mismatch and congruence between taxonomic, phylogenetic and functional diversity: the need for integrative conservation strategies in a changing world. Ecol. Lett. 13, 1030-1040

Devlin, M., Best, M., Haynes, D., 2007. Implementation of the Water Framework Directive in European marine waters. Mar. Pollut. Bull. 55, 1-2.

Elser, J.J., Bracken, M.E.S., Cleland, E.E., Gruner, D.S., Harpole, W.S., Hillebrand, H., Ngai, J.T., Seabloom, E.W., Shurin, J.B., Smith, J.E., 2007. Global analysis of nitrogen and phosphorus limitation of primary producers in freshwater, marine and terrestrial ecosystems. Ecol. Lett. 10, 1135-1142.

Ferdeghini, F., Acunto, S., Cocito, S., Cinelli, F., 2000. Variability at different spatial scales of a coralligenous assemblage at Giannutri Island (Tuscan Archipelago, northwest Mediterranean). Hydrobiologia 440, 27-36.

Flynn, D.F.B., Mirotchnick, N., Jain, M., Palmer, M.I., Naeem, S., 2011. Functional and phylogenetic diversity as predictors of biodiversity-ecosystem-function relationships. Ecology 92, 1573-1581.

Forest, F., Grenyer, R., Rouget, M., Davies, T.J., Cowling, R.M., Faith, D.P., Balmford, A., Manning, J.C., Procheş, S., van der Bank, M., Reeves, G., Hedderson, T.A.J., Savolainen, V., 2007. Preserving the evolutionary potential of floras in biodiversity hotspots. Nature 445, 757-760.

Fraschetti, S., Terlizzi, A., Bussotti, S., Guarnieri, G., D’Ambrosio, P., Boero, F., 2005. Conservation of Mediterranean seascapes: analyses of existing protection schemes. Mar. Environ. Res. 59, 309-332.

Garrabou, J., Ballesteros, E., 2000. Growth of Mesophyllum alternans and Lithophyllum frondosum (Corallinales, Rhodophyta) in the northwestern Mediterranean. Eur J. Phycol. 35, 1-10.

Garrabou, J., Ballesteros, E., Zabala, M., 2002. Structure and dynamics of NorthWestern Mediterranean rocky benthic communities along a depth gradient Estuar. Coast. Shelf Sci. 55, 493-508.

Garrabou, J., Coma, R., Bensoussan, N., Bally, M., Chevaldonné, P., Cigliano, M., Diaz, D., Harmelin, J.G., Gambi, M.C., Kersting, D.K., Ledoux, J.B., Lejeusne, C., Linares, C., Marschal, C., Pérez, T., Ribes, M., Romano, J.C., Serrano, E., Teixido, N., Torrents, O., Zabala, M., Zuberer, F., Cerrano, C., 2009. Mass mortality in Northwestern Mediterranean rocky benthic communities: effects of the 2003 heat wave. Glob. Change Biol. 15, 1090-1103.

Georgiadis, M., Papatheodorou, G., Tzanatos, E., Geraga, M., Ramfos, A., Koutsikopoulos, C., Ferentinos, G., 2009. Coralligène formations in the eastern Mediterranean Sea: morphology, distribution, mapping and relation to fisheries in the southern 
Aegean Sea (Greece) based on high-resolution acoustics. J. Exp. Mar. Biol. Ecol $368,44-58$

Ghiglione, J.F., Palacios, C., Marty, J.C., 2008. Role of environmental factors for the vertical distribution ( $0-1000 \mathrm{~m}$ ) of marine bacterial communities in the NW Mediterranean Sea. Biogeosciences 5, 1751-1764.

Gobert, S., Sartoretto, S., Rico-Raimondino, V., Andral, B., Chery, A., Lejeune, P., Boissery, P., 2009. Assessment of the ecological status of Mediterranean French coastal waters as required by the Water Framework Directive using the Posidonia oceanica Rapid Easy Index: PREI. Mar. Pollut. Bull. 58, 1727-1733.

Gower, J.C., 1971. A general coefficient of similarity and some of its properties. Biometrics 27, 857-871.

Grall, J., Hall-Spencer, J.M., 2003. Problems facing maerl conservation in Brittany. Aquat. Conserv. Mar. Freshw. Ecosyst. 13, 55-64.

Guillot, G., Rousset, F., 2013. Dismantling the Mantel tests. Methods Ecol. Evol. 4, 336-344.

Guiry, M.D., Guiry G.M., 2013. Available at: http://www.algaebase.org.

Hiemstra, P.H., Pebesma, E.J., Heuvelink, G.B.M., Twenhofel, C.J.W., 2010. Using rainfall radar data to improve interpolated maps of dose rate in the Netherlands. Sci. Total Environ. 409, 123-133.

Hofrichter, R., 2004. El mar mediterraneo I: Fauna, Flora, Ecologia. Omega, Barcelona. Hofrichter, R., 2005. El mar mediterraneo II: Fauna, Flora, Ecologia. Omega, Barcelona.

Hooper, D.U., Chapin III, F.S., Ewel, J.J., 2005. Effects of biodiversity on ecosystem functioning: a consensus of current knowledge. Ecol. Monogr. 75, 3-35.

Kamenos, N.A., Moore, P.G., Hall-Spencer, J.M., 2004. Nursery-area function of maerl grounds for juvenile queen scallops Aequipecten opercularis and other invertebrates. Mar. Ecol. Prog. Ser. 274, 183-189.

Kipson, S., Fourt, M., Teixidó, N., Cebrian, E., Casas, E., Ballesteros, E., Zabala, M., Garrabou, J., 2011. Rapid biodiversity assessment and monitoring method for highly diverse benthic communities: a case study of mediterranean coralligenous outcrops. PLoS ONE 6, e27103.

Kohler, K.E., Gill, S.M., 2006. Coral point count with excel extensions (CPCe): a visual basic program for the determination of coral and substrate coverage using random point count methodology. Comput. Geosci. 32, 1259-1269.

Legendre, P., Legendre, L., 2012. Complex ecological data sets. Numer. Ecol. (Dev. Environ. Model.), 1-57.

Legendre, P., Mi, X., Ren, H., Ma, K., Yu, M., Sun, I.-F., He, F., 2009. Partitioning beta diversity in a subtropical broad-leaved forest of China. Ecology 90, 663-674.

Littler, M.M., 1991. Deep-water rhodolith distribution, productivity, and growth history at sites of formation and subsequent degradation. J. Exp. Mar. Biol. Ecol. 150, $163-182$.

Lloret, J., Demestre, M., Sánchez-Pardo, J., 2007. Lipid reserves of red mullet (Mullus barbatus) during pre-spawning in the northwestern Mediterranean. Sci. Mar. 71, 269-277.

McMahon, M.M., Sanderson, M.J., 2006. Phylogenetic supermatrix analysis of GenBank sequences from 2228 papilionoid legumes. Syst. Biol. 55, 818-836.

Meinesz, A., Blanfuné, A., 2015. 1983-2013: Development of marine protected areas along the French Mediterranean coasts and perspectives for achievement of the Aichi target. Mar. Policy 54, 10-16.

Molleman, F., Kop, A., Brakefield, P.M., Vries, P.J., Zwaan, B.J., 2006. Vertical and temporal patterns of biodiversity of fruit-feeding butterflies in a tropical forest in Uganda. Biodivers. Conserv. 15, 107-121.

Mouillot, D., Albouy, C., Guilhaumon, F., Ben Rais Lasram, F., Coll, M., Devictor, V., Meynard, C.N., Pauly, D., Tomasini, J.A., Troussellier, M., Velez, L., Watson, R., Douzery, E.J.P., Mouquet, N., 2011. Protected and threatened components of fish biodiversity in the Mediterranean sea. Curr. Biol. 21, 1044-1050.

Mouillot, D., Graham, N.a.J., Villéger, S., Mason, N.W.H., Bellwood, D.R., 2013. A functional approach reveals community responses to disturbances. Trends Ecol. Evol. $28,167-177$

Mouquet, N., Devictor, V., Meynard, C.N., Munoz, F., Bersier, L.-F., Chave, J., Couteron, P., Dalecky, A., Fontaine, C., Gravel, D., Hardy, O.J., Jabot, F., Lavergne, S., Leibold, M., Mouillot, D., Münkemüller, T., Pavoine, S., Prinzing, A., Rodrigues, A.S.L., Rohr, R.P., Thébault, E., Thuiller, W., 2012. Ecophylogenetics: advances and perspectives. Biol. Rev. Camb. Philos. Soc. 87, 769-785

Ndiribe, C., Pellissier, L., Antonelli, S., Dubuis, A., Pottier, J., Vittoz, P., Guisan, A., Salamin, N., 2013. Phylogenetic plant community structure along elevation is lineage specific. Ecol. Evol. 3, 4925-4939.

Pardini, R., de Souza, S.M., Braga-Neto, R., Metzger, J.P., 2005. The role of forest structure, fragment size and corridors in maintaining small mammal abundance and diversity in an Atlantic forest landscape. Biol. Conserv. 124, 253-266.

Pavoine, S., Bonsall, M.B., 2011. Measuring biodiversity to explain community assembly: a unified approach. Biol. Rev. 86, 792-812.

Pavoine, S., Dufour, A.B., Chessel, D., 2004. From dissimilarities among species to dissimilarities among communities: a double principal coordinate analysis. J. Theor. Biol. 228, 523-537.

Personnic, S., Boudouresque, C.F., Astruch, P., Ballesteros, E., Blouet, S., Bellan-Santini, D., Bonhomme, P., Thibault-Botha, D., Feunteun, E., Harmelin-Vivien, M., Pergent, G., Pergent-Martini, C., Pastor, J., Poggiale, J.C., Renaud, F., Thibaut, T., Ruitton, S., 2014. An ecosystem-based approach to assess the status of a mediterranean ecosystem, the Posidonia oceanica seagrass meadow. PLOS ONE 9, e98994.

Piazzi, L., Balata, D., 2011. Coralligenous habitat: patterns of vertical distribution of macroalgal assemblages. Sci. Mar. 75, 399-406

Piazzi, L., Balata, D., Cecchi, E., Cinelli, F., Sartoni, G., 2009. Species composition and patterns of diversity of macroalgal coralligenous assemblages in the northwestern Mediterranean Sea. J. Nat. Hist. 44, 1-22
Pilar Olivar, M., Emelianov, M., Villate, F., Uriarte, I., Maynou, F., Álvarez, I., Morote E., 2010. The role of oceanographic conditions and plankton availability in larva fish assemblages off the Catalan coast (NW Mediterranean). Fish. Oceanogr. 19, 209-229.

R Development Core Team, 2014. R: A Language and Environment for Statistical Computing. R Foundation for Statistical Computing, Vienna, Austria, ISBN 3 900051-07-0.

Ricotta, C., 2005. Additive partitioning of Rao's quadratic diversity: a hierarchical approach. Ecol. Model. 183, 365-371.

Ricotta, C., Bacaro, G., Marignani, M., Godefroid, S., Mazzoleni, S., 2012. Computing diversity from dated phylogenies and taxonomic hierarchies: does it make a difference to the conclusions? Oecologia 170, 501-506.

Ricotta, C., Szeidl, L., 2009. Diversity partitioning of Rao's quadratic entropy. Theor Popul. Biol. 76, 299-302.

Rodriquez-Prieto, C., Ballesteros, E., Boisset, F., Afonso-Carrillo, J., 2013. Guía de las macroalgas y fanerógamas marinas del Mediterráneo occidental. Omega, Madrid.

Roquet, C., Thuiller, W., Lavergne, S., 2013. Building megaphylogenies for macroecology: taking up the challenge. Ecography 36, 013-026.

Ruíz, J.M., Boudouresque, C.F., Enríquez, S., 2009. Mediterranean seagrasses. Bot. Mar. 52, 369-381.

Safi, K., Cianciaruso, M.V., Loyola, R.D., Brito, D., Armour-Marshall, K., Diniz-Filho, J.A.F., 2011. Understanding global patterns of mammalian functional and phylogenetic diversity. Philos. Trans. R. Soc. Lond. Ser. B Biol. Sci. 366, 2536-2544.

Sartoretto, S., Verlaque, M., Laborel, J., 1996. Age of settlement and accumulation rate of submarine "coralligène" ( -10 to $-60 \mathrm{~m}$ ) of the northwestern Mediterranean Sea; relation to Holocene rise in sea level. Mar. Geol. 130, 317-331.

Serrano, X., Baums, I.B., O'Reilly, K., Smith, T.B., Jones, R.J., Shearer, T.L., Nunes, F.L.D., Baker, A.C., 2014. Geographic differences in vertical connectivity in the Caribbean coral Montastraea cavernosa despite high levels of horizontal connectivity at shallow depths. Mol. Ecol. 23, 4226-4240.

Smith, S.A., Donoghue, M.J., 2008. Rates of molecular evolution are linked to life history in flowering plants. Science 322, 86-89.

Srivastava, D.S., Cadotte, M.W., MacDonald, a A.M., Marushia, R.G., Mirotchnick, N. 2012. Phylogenetic diversity and the functioning of ecosystems. Ecol. Lett. 15, 637-648

Swenson, N.G., 2011. The role of evolutionary processes in producing biodiversity patterns, and the interrelationships between taxonomic, functional and phylogenetic biodiversity. Am. J. Bot. 98, 472-480.

Swenson, N.G., Enquist, B.J., Pither, J., Thompson, J., Zimmerman, J.K., 2006. The problem and promise of scale dependency in community phylogenetics. Ecology 87 2418-2424

Teixidó, N., Casas, E., Cebrián, E., Linares, C., Garrabou, J., 2013. Impacts on coralligenous outcrop biodiversity of a dramatic coastal storm. PLOS ONE 8, http://dx doi.org/10.1371/journal.pone.0053742.

Thingstad, T.F., Krom, M.D., Mantoura, R.F.C., Flaten, G.A.F., Groom, S., Herut, B., Kress, N., Law, C.S., Pasternak, A., Pitta, P., Psarra, S., Rassoulzadegan, F., Tanaka, T., Tselepides, A., Wassmann, P., Woodward, E.M.S., Riser, C.W., Zodiatis, G., Zohary, T. 2005. Nature of phosphorus limitation in the ultraoligotrophic eastern Mediterranean. Science 309, 1068-1071.

UNEP-MAP-RAC/SPA, 2011. Proposal for the definition of standard methods for inventorying and monitoring coralligenous and maërl populations, Tunis.

Vasconcelos, H.L., Vilhena, J.M.S., 2006. Species turnover and vertical partitioning of ant assemblages in the Brazilian Amazon: a comparison of forests and savannas. Biotropica 38, 100-106

Veech, J.A., Crist, T.O., 2010. Toward a unified view of diversity partitioning. Ecology 91, 1988-1992.

Villéger, S., Mason, N.W.H., Mouillot, D., 2008. New multidimensional functiona diversity indices for a multifaceted framework in functional ecology. Ecology 89, 2290-2301.

Villeger, S., Miranda, J.R., Hernandez, D.F., Mouillot, D., 2012. Low functional betadiversity despite high taxonomic beta-diversity among tropical estuarine fish communities. PLoS ONE 7, e40679.

Villéger, S., Novack-Gottshall, P.M., Mouillot, D., 2011. The multidimensionality o the niche reveals functional diversity changes in benthic marine biotas across geological time. Ecol. Lett. 14, 561-568.

Virgilio, M., Airoldi, L., Abbiati, M., 2006. Spatial and temporal variations of assemblages in a Mediterranean coralligenous reef and relationships with surface orientation. Coral Reefs 25, 265-272.

Walla, T.R., Engen, S., DeVries, P.J., Lande, R., 2004. Modeling vertical beta-diversity in tropical butterfly communities. Oikos 107, 610-618.

Webb, C.O., 2000. Exploring the phylogenetic structure of ecological communities an example for rain forest trees. Am. Nat. 156, 145-155.

Wermelinger, B., Flückiger, P.F., Obrist, M.K., Duelli, P., 2007. Horizontal and vertica distribution of saproxylic beetles (Col., Buprestidae, Cerambycidae, Scolytinae) across sections of forest edges. J. Appl. Entomol. 131, 104-114.

Wood, S.N., Augustin, N.H., 2002. GAMs with integrated model selection using penalized regression splines and applications to environmental modelling. Ecol. Model. 157, 157-177.

Ye, W., Liu, X., Lin, S., Tan, J., Pan, J., Li, D., Yang, H., 2009. The vertical distribution of bacterial and archaeal communities in the water and sediment of Lake Taihu. FEMS Microbiol. Ecol. 70, 107-120.

Zinger, L., Amaral-Zettler, L.a., Fuhrman, J.a., Horner-Devine, M.C., Huse, S.M., Welch, D.B.M., Martiny, J.B.H., Sogin, M., Boetius, A., Ramette, A., 2011. Global pattern of bacterial beta-diversity in seafloor and seawater ecosystems. PLoS ONE 6, e24570 